NASA Technical Memorandum 100673

\title{
DIRECT SIMULATION OF AFE FOREBODY AND WAKE FLOW WITH THERMAL RADIATION
}

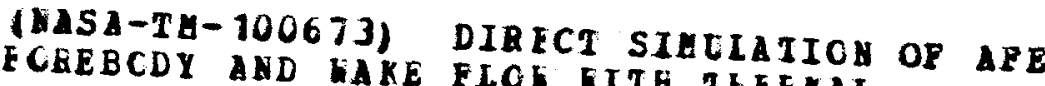 \\ EAIIATICA (NASL) FLCh TITB TEEELAL \\ CSCL 2OD

James N. Moss

Joseph M. Price

September 1988

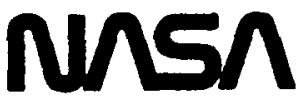

National Aeronautics and Space Administration 


\title{
DIRECT SIMULATION OF AFE FOREBODY AND WAKE FLOW \\ WITH THERMAL RADIATION
}

\author{
James N. Moss and Joseph M. Price \\ NASA Langley Research Center \\ Hampton, Virginia 23665-5225
}

\begin{abstract}
Calculated results for the flowfield structure and surface quantities are presented for an axisymmetric representation of an aeroassist flight experiment vehicle. The direct simulation Monte Carlo (DSMC) method is used to perform the calculations, since the flow is highly nonequilibrium about the vehicle during both the compresston and expansion phases. The body configuration is an elliptically blunt nose followed by a skirt with a circular radius and an afterbody. Freestream conditions correspond to a single point along the entry trajectory at an altitude of $90 \mathrm{~km}$ and a velocity of $9.9 \mathrm{~km} / \mathrm{s}$. The calculations account for nonequilibrium in the translational and internal modes, dissociation, lonization, and thermal radiation. The degree of dissociation is large, but the maximum ionization is only about 2 percent by mole fraction. The blunt forebody flow experiences a high degree of thermal nonequilibrium in which the translational temperature is generally greater than the internal temperature. However, as the flow expands about the aerobrake skirt and afterbody, the internal temperature is generally greater than the translational temperature. Furthermore, the calculated results clearly show mass separation effects in the wake with a preferential increase in the concentration of the light (atomic) species relative to their values at the corner expansion on the aerobrake skirt. Forebody heating is dominated by the convective
\end{abstract}


component, however, the stagnation point radiative heating under the assumption of no absorption is about 12 percent of the convective value. Afterbody heating is very small compared with forebody values.

\section{Nomenclature}

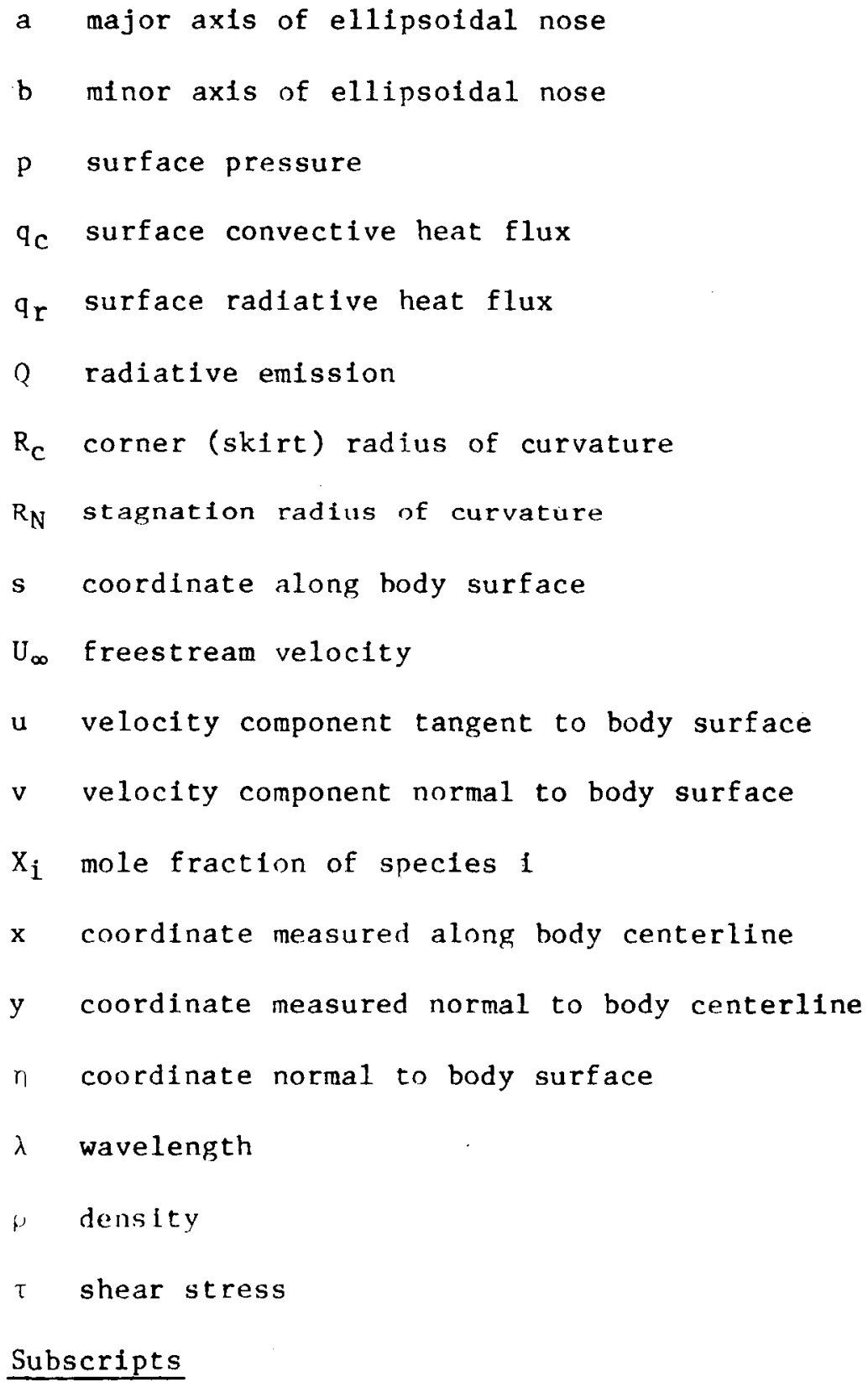


Introduction

The potential economic benefit of a reusable aeroassisted orbital transfer vehfcle (AOTV) over its all-propulsive counterpart is such that AOTV's are being actively studied ${ }^{1-3}$ as a class of vehicles for providing transporation between low-Earth orbit and varlous locations within the inner solar system. Results of the studies show that the preferred vehicle concept for these missions is one which has a low ballistic coefficient and features a large, blunt lightweight aerobrake. On return from high-Earth orbit or the Moon, the vehicles will enter the Earth's atmosphere with a velocity of approximately $10 \mathrm{~km} / \mathrm{s}$, fly a roll-modulated trajectory with a perigee of 75 to $100 \mathrm{~km}$, skip back out of the atmosphere, and rendezvous with a space station after having achieved the velocity decrement required for capture Into low-Earth orbit.

Both the velocity and altitude for the atmospheric pass are sufficient1y high to produce a highly nonequilibrium flow environment where hightemperature and low-density gas effects will significantly impact the aerodynamic and thermal loads. Since such an environment cannot be simulated in ground-based test facilities, the ultimate design of the AOTV's will rely heavily on numerical calculations.

In order to advance the technology for the AOTV vehicles, the National Aeronautics and Space Administration has undertaken the Aeroassist F1ight Experiment ${ }^{3}$ (AFE). The AFE is a subscale vehicle [Fig. 1(a)] that will be launched from the Space Shuttle, fly a representative aeroassist trajectory, and be recovered by the Shuttle. Flight measurements will provide an opportunity for clarifying issues associated with a radiating nonequilibrium flowfleld where rarefaction effects will be present for a significant portion of the atmospheric encounter. 
Two numerical simulation approaches are being developed and applied to the problem of calculating the flow about AFE and AOTV vehicles. One is the continuum approach (Refs. 4-7 are representative of recent publications), and the other is the particle approach as implemented through the direct simulation Monte Carlo (DSMC) method (Refs. 8-13). In the present paper, the DSMC method is applied to a single point along an AFF entry trajectory corresponding to an altitude of $90 \mathrm{~km}$ and a velocity of $9.9 \mathrm{~km} / \mathrm{s}$. An axisymmetric representation of the AFE vehicle is used to reduce the computational effort. The upper rather than the lower portion of the AFE vehicle is considered so that the most severe heating can be calculated for the carrier panel (Fig. 1) which is shadowed by the aerobrake. The present study is an extension of the work reported in Ref. 12, in that the AFE vehicle afterbody is used rather than an arbitrary afterbody. Furthermore, the cell grid and time steps used in the present study are much smaller than those used in Ref. 12. Results for radiative and convective heating are presented along both the blunt forebody and the afterbody carrier panel. Also, details concerning the flowfield structure for an 11-species dissociation and ionizing gas mixture are presented.

\section{DSMC Method}

The direct simulation Monte Carlo method involves the simultaneous computation of the trajectories of some thousands of simulated molecules in simulated physical space. The time parameter in the simulation may be Identified with real time, and the flow is always calculated as an unsteady flow. The inftial conditions do not depend on a prediction of the flowfield but can be specified in terms of states, such as a uniform flow or a vacuum, that permit exact specification. Any steady flow is the large time state of 
the unsteady flow. There are no iterative procedures and no stability or convergence problems. A computational grid is required only in physical space, rather than phase space, and then only for the choice of collision pairs and the sampling of flow properties. The boundary conditions are specifled in terms of the behavior of individual molecules, rather than the molecular distribution function, and all procedures may be specified such that the computation time is Inearly dependent on the number of molecules. Advantage may be taken of flow symmetries to reduce the number of dimensions of the grid and the number of position coordinates that need to be stored for each molecule, but the collisions are always calculated as three-dimensional phenomena.

\section{Gas Model}

This section presents a brief summary of the models used to describe molecular collisions, internal energy, chemical reaction, and thermal radiation. The gas models for reacting air included 11 chemical species, 41 chemical reactions, 35 electronic states or groups of states, and 26 boundbound radiative transitions for molecular band and atomic events. For a more detailed description along with tabulated data, see Refs. 10 and 12.

The variable hard sphere (VHS) model 14 was used for the inter-molecular collisions. This is the simplest model that satisfies the basic requirement to model both the coefficient of viscosity and the temperature dependence of this coefficient. The viscosity coefficient was assumed to be proportional to the 0.7 power of temperature, and the molecular dlameters at a reference temperature of $288 \mathrm{~K}$ were $0.396,0.407,0.300$, 0.300 , and $0.400 \mathrm{~nm}$ for $0_{2}, \mathrm{~N}_{2}, 0, \mathrm{~N}$, and $\mathrm{NO}$, respectively. Molecular diameters for the ions were assumed to be the same as for the five corresponding neutral species. For the electron, the effective elastic 
diameter is generally assumed to be less than that of the atoms and molecules. A reference diameter of $0.1 \mathrm{~nm}$ was chosen for the present study. For the rotational and vibrational energy modes, the Borgnakke-Larsen 15 model is used. The essential feature of this model is that a fraction of the collisions are regarded as completely inelastic, and for these, new values of the translational and internal energies are sampled from the distributions of these quantities that are appropriate to an equilibrium gas. The remainder of the molecular collisions are regarded as elastic. The fraction of inelastic collisions can be chosen to match the real gas relaxation rate. For this study, constant relaxation collision numbers of 5 and 50 were used for the rotational and vibrational modes, respectively. The effective number of degrees of freedom in the partially excited vibrational states is calculated from the harmonic oscillator theory. The procedures for the nonequilibrium chemical reactions are extensions of the elementary collision theory of chemical physics. The binary reaction rate is obtained as the product of the collision rate for collisions with energy in excess of the activation energy and the probability of reaction or steric factor. A form of the collision theory ${ }^{16}$ that is consistent with the VHS model has been used to convert these temperature-dependent rate coefficients of continuum theory into collisional-energy-dependent steric factors. The reactive cross section is the product of the steric factor and the elastic cross section. The chemical reactions considered in this study consisted of 41 reactions for 11 species, and the data are listed in Ref. 10 . Accompanying the partial ionization of a gas are electronic excitation and thermal radiation. Radiation from bound-bound transitions between electronic states can be significant in $10-\mathrm{km} / \mathrm{s}$ flows. The procedures used for calculating the population of electronic states are analogous to the 
Borgnakke-Larsen model that has proved successful for the rotational and vibrational degrees of freedom. For a specifled fraction of the collistons, the electronic states are sampled from the equilibrium distribution appropriate to the effective temperature based on the sum of the relative translational energy and the electronic energy of the molecules in the collision. (Note that this temperature is defined on the basis of the relative energy for the single collision pair.) The specified fraction is related to the ratio of the cross section for electronic state excitation to the elastic cross section. Separate fractions are specified for collisions of each species with neutrals, ions, and electrons. (See Ref. 10 for a tabulation of the fraction of collisions that lead to electronic excitation and the rationale for the selection of the fractions.) Unlike the procedures for the rotational and vibrational modes in which each molecule is assigned a single energy or state, each molecule is assigned a distribution over all the avallable electronic states. This overcomes the computational problems associated with radiation from sparsely populated states.

The molecular band system is the same as that employed by Park17 and involves the electronic states of molecular oxygen, neutral and ionized nitrogen, and nitric oxide. Radiation from six molecular hand transitions is included in the simulation with a specified mean time $t$ :s spontaneous emission for each radiating state. The actual time to enission is exponentially distributed about this mean time.

Because the number of electronic states and radiative transitions is large for the atomic species, both the electronic states and radiative transitions are combined to form a manageable number of groups. Eight groups of electronic states are used for both atomic oxygen and atomic nitrogen (Ref. 10). The radiative transitions are grouped into seven groups for 
atomic oxygen and thirteen groups for atomic nitrogen. (Ref. 10 tabulates specific data concerning the electronic state and radiative transitions.)

The radiation absorption model currently implemented in the DSMC simulation is one in which the photon will be absorbed only by atoms or molecules in the end state of the transition that produced the photon. If the number density of absorbing molecules in $\mathrm{n}_{\mathrm{a}}$ and the absorption cross section is $u_{a}$, the probability of absorption of a photon traversing a length $\Delta \ell$ while moving through a cell is

$$
\Delta \ell \mathrm{n}_{\mathbf{a}} \sigma_{\mathbf{a}} \cdot
$$

Each time a radiation even occurs, the orientation is chosen such that all directions are equally possible, and the trajectory of the photon is followed until it is absorbed in the Flow, is absorbed at the surface, or exits from the flow. In the present application, absorption is assumed to be zero.

\section{Conditions for Calculations}

The freestream conditions for an altitude of $90 \mathrm{~km}$ are listed in Table 1 alnng with selected freestream parameters. The freestream mole fractions were $0.209,0.787$, and 0.003 for oxygen, nitrogen, and atomic oxygen, respectively. The surface temperature is assumed constant at $1000 \mathrm{~K}$ on the forebody of the aerobrake and constant at $300 \mathrm{~K}$ for all surfaces in the shadow of the aerobrake. Also, the surface is assumed to be diffuse with full thermal accommodation and to promote recombination of atoms, ions, and electrons. Recombination probabilities appropriate for the Shuttle thermal protection tiles were imposed for atom recombination, and the ions and electrons are assumed to be fully recombined at the surface.

The AFE vehtcle is composed of three basic components: the aerobrake, the carrier vehicle, and the main propulsion unit [Fig. 1(a)]. The aerobrake 
is a blunt elliptic cone raked off at the base and fitted with a skirt-type afterbody. Therefore, the vehicle is a three-dimensional configuration and has an effective diameter of about $4 \mathrm{~m}$. The present calculations are for an axisymmetric representation of the upper portion of the AFE to examine the maximum heating to the carrier and to reduce the computational effort even though general three-dimensional DSMC $\operatorname{codes}^{13}$ are currently being applied to the actual AFE configuration at higher altitude conditions. For the axisymmetric calculations, the geometry shown in Fig. 1(b) was used.

The computational domain for the DSMC simulation is shown in Fig. 2 where the outermost boundary is sufficiently displaced from the vehicle so as to capture the flowfield disturbance generated by the vehicle. The outflow boundary downstream of the vehicle is treated as a vacuum boundary. The computational domain in subdivided into 23 regions, and each region is further subdivided into computational cells. (Cells are quadrilaterals.) The computational time step and the physical scaling relation (relates the number of simulated molecules to the actual number of physical molecules) are prescribed independently for each region to achieve an adequate number of modeled molecules per cell (order of 10 ) and to ensure that the computational time step be less than the molecular mean transit time in each cell. The scaling relation and the time step were constrained to preserve flux continuity at the region boundaries. In addition, the cell size was selected such that the dimension normal to the body was less than the local mean free path length (minimum cell dimensions ranged from $2.5 \times 10^{-5}$ to $0.20 \mathrm{~m}$ ). A total of 2561 cells was used in the simulation, and the number of simulated molecules was 63,000 . 
Results and Discussion

The flowfield structure and surface quantities resulting from a DSMC simulation are highlighted to demonstrate the change in these quantities as the flow expands from the stagnation region of the aerobrake to the skirt section and finally to the carrier panel which is shadowed by the aerobrake. The first section reviews existing calculations for the 90-km case contrasting the continuum and ISMC results. This is followed by a review of the present calculation for the flowfield structure by indicating the extent of thermal and chemical nonequilibrium and the region within the flowfield where radiation emission dominates. Finally, the surface quantities in terms of heating rate, pressure, and shear are presented.

Existing Results for 90-km Case

The AFE entry condition at $90 \mathrm{~km}$ has been examined in several recent studies.5,6,11,12 Results of Ref. 11 for a 5-species dissoctating air model show that the local Knudsen number, where the characteristic length is based on the density gradient normal to the body, is greater than 0.1 in the region near the surface and throughout the shock wave region. Recall that the Navier-Stokes equations are valid 18 only as long as the Chapman-Enskog theory for the transport properties is valid and that this conditinn is satisfled if the local Knudsen number based on macroscropic gradients is small compared with unity (about 0.1 or less). This condition suggests that the modeling of the flow at $90 \mathrm{~km}$, even along the stagnation streamline, using the Navier-Stokes (NS) equations is deficient for this problem. Evidence of this is suggested in Ref. 5 where stagnation profile quantities obtained using viscous-shock-1ayer (VSL) and NS (shock capturing) calculations are compared with the DSMC results of Refs. 11 and 12. The comparisons show major differences in density and composition profiles. For 
example, near the center of the shock wave, the density calculated with the NS mode1 [(Ref. 5, Fig. $10(a)$ ] is about a factor of two greater than the DSMC results, and these differences persist throughout most of the flow domain. The fact that the NS value for the density is higher indicates that the ratio of speciflc heats should be smaller. Yet the amount of dissociation is less than the DSMC calculation. The problems with this NS calculation are its inablity to describe the shock wave structure under hypersonic conditions (Ref, 19), and also the inconsistency in obtaining the thermodynamic properties for the individual chemical species from curve fits based on the assumption of local thermodynamic equilibrium. Since the population of internal states (rotional, vibrational, and electronic) in a Mach 36 shock wave is quite different from that based on the calculated temperatures of Ref. 5, the ratio of specific heat would be too low and hence the density too high. As for the surface heating, the NS value was 58 percent of the DSMC value for the $90-\mathrm{km}$ entry condition.

Another important comparsion for AFE conditions can be made by comparing the VSL (Ref. 5) and DSMC (Ref. 12) stagnation-point convective heating rate values. The stagnation streamline solutions reported in Ref. 12 were mistakenly reported as being made for a finite catalytic surface. They were actually made for a noncatalytic surface, and this error is carried over in the comparisons of Ref. 5. Once the correction is made, we find that the DSMC and VSt calculations agree the best at perigee conditions (VSL low by about 8 percent) and experience increasing differences with increasing altitude (VSL $10 \mathrm{w}$ by about 40 percent at $90 \mathrm{~km}$ ). Qualitatively, this is the type of behavtor one would expect due to the low-density and high-temperature effects giving rise to a highly nonequilibrium flow. 


\section{Flowfield Structure}

Figure 3 displays selected contours of the local density, expressed as a ratio to the freestream value, for the forebody and near wake region. The density variation is in excess of three orders of magnitude. In the stagnation region, the compression combined with a relatively cool wall produces a maximum density that is 155 times the freestream value. Because of the expansion about the elliptically blunt nose, the density adjacent to the surface decreases to 112 times the freestream in the last cell on the nose, and then with the vary rapid expansion on the skirt, to a value of 9.5 in the last cell on the skirt. Along the carrier panel, the density is only a small fraction of the freestream value.

Variation of flow properities in the body normal (1) direction is presented in Figs. 4 through 6 (density and velocity in Fig. 4, translational and internal temperature in Fig. 5, and species mole fractions in Fig. 6) where each flgure presents data at three body stations: part (a) along the stagnation streamline, part (b) along the last column of cells above the skirt section, and part (c) above the carrier panel at an $x$ location of $0.8 \mathrm{~m}$.

Along the stagnation streamline, the various profiles show no evidence of a distinct shock wave, only a gradual merging of the shock wave and shock layer. The translational temperature [Fig. 5(a)] peaks at about $40,000 \mathrm{~K}$ while the internal temperature (defined in terms of the rotational and vibrational energies and the number of internal degrees of freedom) has a peak value of about $17,000 \mathrm{k}$. Thermal nonequilibrium is evident throughout the flowfield. As the flow expands about the skirt $[F i g .5(b)]$ and on to the carrier panel [Fig. 5(c)], the translational temperature decreases by almost a factor of four, whereas the peak internal temperature decreases to about 60 
percent of Its peak stagnation value. Over both the skirt and carrier panel, a substantial portion of the flowfield has a higher internal temperature than the corresponding translational value. Even though the density and temperature decrease substantially as the flow expands on to the skirt [Fig. 4(b) and 5(b)], the gas remains highly dissociated as is indicated in Fig. 6 where the mole fraction profiles for only the electron and neutral species are shown. The electron concentration is 2 percent or less. For the region immediately above the surface, the gas composition is primarily three species: atomic and molecular nitrogen and atomic oxygen. The dominant species is atomic nitrogen with a mole fraction value of approximately 0.6 . As the gas expands from the skirt corner [Fig 6(b)] over the carrier panel, mass separation effects are evident where concentration of heavy species $\left(\mathrm{N}_{2}\right)$ decreases in relation to the light (atomic species). Figures $7(a)$ through $7(c)$ show the radiative emission profiles along body normals at the same three body locations. The peak value at each of the three body stations occurs near the location where the internal temperature is a maximum. In contrast to the results of Ref. 6 , the maximum total radiation emission occurs along the stagnation streamline and then decreases substantially downstream of the stagnation region. In fact, the vartation is so large that a tangent slab approximation (an approximation often used in calculating the surface radiative heating, but not used in the present calculation) would probably introduce significant ercors, particularly on the skirt and carrier panel. Beyond the skirt corner expansion, the emission decreases rapidly with increasing distance downstream of the corner. Also, the emission is confined to a region that is radially above the corner. Surface Distributions

Figures 8 and 9 present the calculated radiative and convective heating distributions, respectively, along the aerobrake and carrier panel. In 
concert with the radiative emission, the surface radiative heating is a maximum in the stagnation region and decreases along the aerobrake. The radiat fe heat flux to the skirt is only 10 percent of the stagnalion value. For the carrier panel, the radiative flux is about 1 percent of the stagnation value. For the aerobrake, Fig. 8 presents both the total radiative flux distribution and that resulting from bound-bound transitions where the wavelength is greater than $0.2 \mu$. The present calculation with no absorption shows that a significant fraction (62 percent in the stagnation region and 24 percent on the skirt) of the aerobrake heating originates at the shorter wavelengths. If radiation absorption were included, then the contribution of the shorter wavelength radiation would decrease, since the gas is almost transparent to the longer wavelength radiation, but there is significant absorption of the ultraviolet radiation. This effect has been previouslylo demonstrated with the absorption model currently implemented in the DSMC method.

The present calculation for radiative heating differs from the preliminary axisymmetric results reported in Ref. 12 in several respects. First, the magnitude of the stagnation radiative heating is about two times that reported in Ref. 12. Also, the present calculation shows a significant decrease in heating with increasing distance from the stagnation region, whereas the previous values remained approximately constant. Three differences between the previous and current calculations exist. First, the axisymmetric calculation reported in Ref. 12 used a constant absorption cross section of $5.0 \times 10^{-20} \mathrm{~m}^{2}$. The present calculation used a value of zero. Inclusion of absorption causes a larger reduction in the stagnation region than on the skirt. The second and third differences were that the current calculation used a much smaller cell size and time step. of more 
importance for the radiation calculation is the time step, because the time step was about two orders of magnitude smaller such that it was comparable to the smallest mean radiation lifetime.

In the stagnation region, for example, most of the radiation to the surface is due to atomic nitrogen (67 percent from atomic nitrogen, 26 percent from molecular bands, and 7 percent from atomic oxygen). In the region where the radiation emission is a maximum, atomic nitrogen has a mole fraction of about 0.55 .

Figure 9 presents the convective heating distribution on the aerobrake and carrier panel. The calculation shows that the convective heating decreases gradually from a maximum at the stagnation point on the elliptical nose and then decreases significantly as the flow accelerates about the circular skirt. This trend is consistent with previous DSMC calculations 11 but differs from those reported in Ref. 6 , where the maximum heating occurred on the elliptic nose, but downstream of the stagnation point. The magnitude of the heating on the carrier panel is small, increasing from about 1 percent of the stagnation-point value at the carrier-aerobrake juncture to about 5 percent at the most downstream location.

Figures 10 and 11 present the corresponding surface pressure and skin friction distributions, respectively, for the aerobrake. The pressure distribution has the same qualitative behavior as the convective heating distribution. The skin friction is a maximum on the circular skirt.

\section{Concluding Remarks}

Through the use of the DSMC method, flowfield structure and surface quantities about an axisymmetric representation of the AFE vehicle have been 
calculated for entry conditions at $90 \mathrm{~km}$. Results of the calculation which Include the effects of ionization and thermal radiation show the following:

(1) Convectlve heating is dominant, yet thermal radiation is significant.

(2) For zero absorption, a significant portion of the surface radiative flux is due to ultraviolet radiation.

(3) The carrier panel heating rates are small with values ranging from 1 to 5 percent of the corresponding stagnation-point value.

(4) The flow is highly nonequilibrium with mass separation effects evident in the wake region.

\section{References}

1Pioneering the Space Frontier: The Report of the National Commission on Space, 1986, Bantam Books, New York.

2Walberg, G. D., "Aeroassisted Orbit Transfer-Window Opens on Missions," Astronautics and Aeronautics, Vol. 21, No. 11, November 1983, pp. $36-43$.

3Walberg, G. D., Siemers, P. M., Calloway, R. L., and Jones, J. J., "The Aeroassist F1ight Experiment," IAF Paper 87-197, October 1987. ${ }^{4}$ Gnoffo, P. A. and Green, F. A., "A Computational Study of the Flowfield Surruonding the Aeroassist Flight Experiment Vehicle," AIAA Paper 87-1575, June 1987.

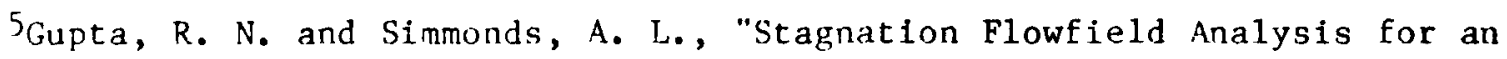
Aernassist Flight Experiment Vehicle," AIAA Paper 88-2613, June 1988. ${ }^{6}$ Candler, G. and Park, C., "The Computation of Radiation from Nonequilibrium Hypersonic Flows," AIAA Paper 88-2678, June 1988. 
${ }^{7} \mathrm{Li}, \mathrm{C}$. and Wey, T. C. "Numerical Simulation of Hypersonic Flow Over an Aeroassist Flight Experiment Vehicle, "AIAA Paper 88-2675, June 1988.

${ }^{8}$ Bird, G. A., "Low-Density Aerothermodynamics," Progress in Astronautics and Aeronautics: Thermophysical Aspects of Re-Entry Flows, edited by J. N. Moss and C. D. Scott, Vol. 103, 1986, pp. 3-24.

9Bird, G. A., "Direct Simulation of Typical AOTV Entry Flows," AIAA Paper $86-1310$, June 1986.

10Bird, G. A. "Nonequilibrium Radiation During Re-Entry at $10 \mathrm{~km} / \mathrm{s}, "$ AIAA Paper 87-1543, June 1987.

${ }^{1}$ Dogra, V. K., Moss, J. N., and Simmonds, A. L. "Direct Simulation of Aerothermal Loads for an Aeroassist Flight Experiment Vechicle," AIAA Paper 87-1546, June 1987.

12Moss, J. N., Bird, G. A., and Dogra, V. K., "Nonequilibrium Therma1 Radiation for an Aeroassist Flight Experiment Vehicle," AIAA Paper 88-0081, January 1988.

${ }^{13}$ Celenligil, M. C., Moss, J. N., and Bird, G. A., "Direct Simulation of Three-Dimensiona1 Flow About the AFE Vehicle at High Altitude," loth RGD Symposium, Pasadena, CA, July 1988. 14Bird, G. A., "Monte-Carlo Simulation in an Engineering Context," Progress in Astronautics and Aeronautics: Rarefied Gas Dynamics, Vol. 74, Part 1 , ediced by Sam S. Fisher, 1981, pp. 239-255.

15 Borgnakke, C. and Larsen, P. S., "Statistical Collision Model for Monte Carlo Simulation of Polyatomic Gas Mixtures," Journal of Computation Physics, Vol. 18, 1975, pp. 405-420.

16Bird, G. A. "Simulation of Multi-Dimensional and Chemically Reacting Flows," Rarefield Gas Dynamics, edited by R. Campargue, CEA, Paris, 1979, pp. $365-388$. 
17Park, C., "Calcillation of Nonequililbrium Radiation in the Flight Regines of Aeroassisted Orbital Transfer Vehtcles," Progress in Astronautics and Aeronautics, edited by H. F. Nelson, Vol. 96 of 1985, pp. 395-418.

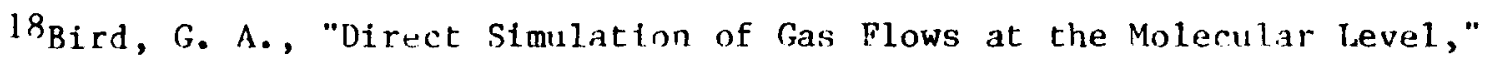
Communications in Applied Numerical Methods, Vol. 4, 1988, pp. 165-172. ${ }^{19}$ Fiscko, K. A. and Chapman, D. R., "Hypersonic Shock Structure with Burnett Terms in the Viscous Stress and Heat Flux," AIAA Paper 88-2733, June 1988. 
Table 1. Freestream Conditions and Parameters

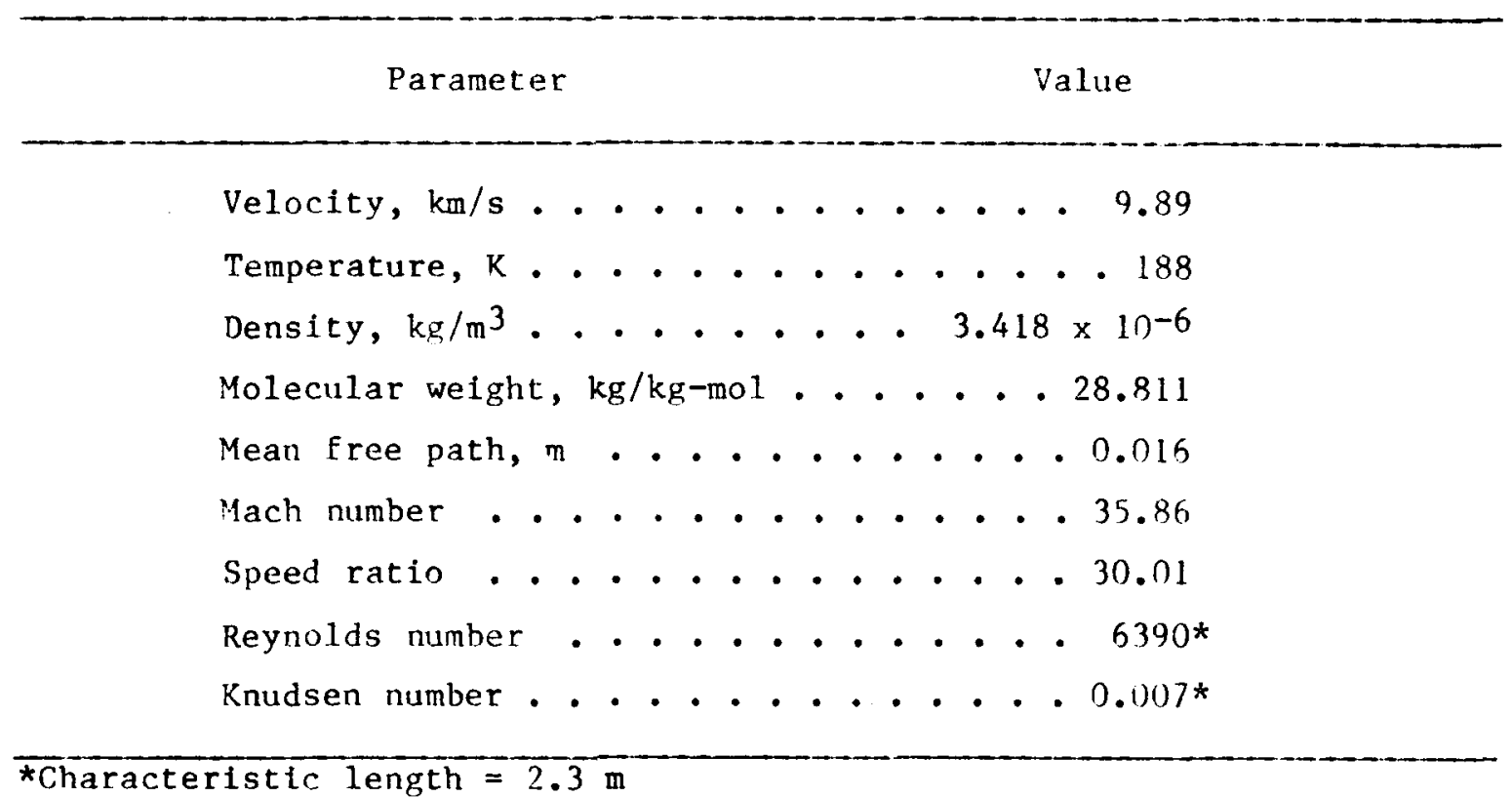




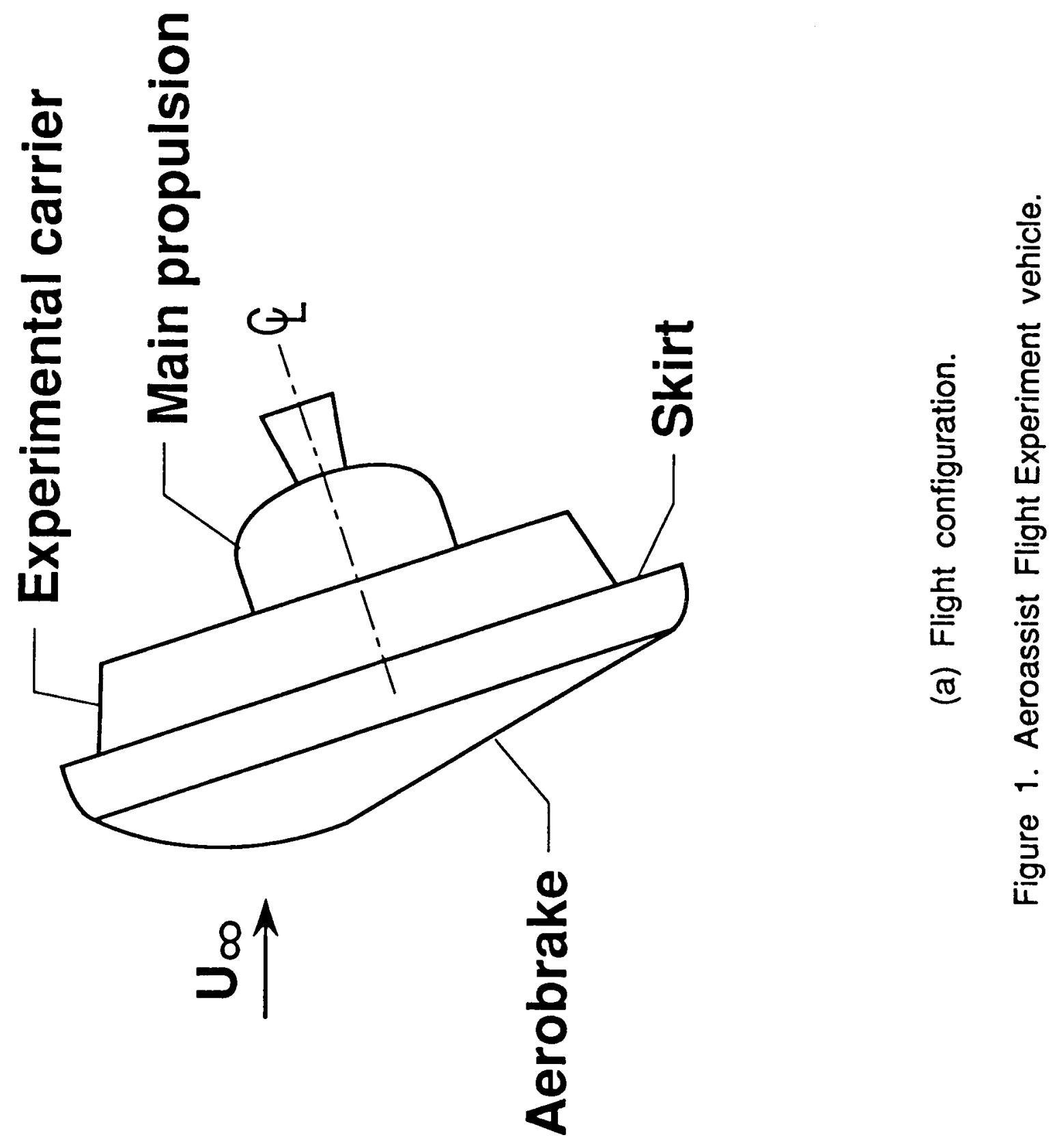




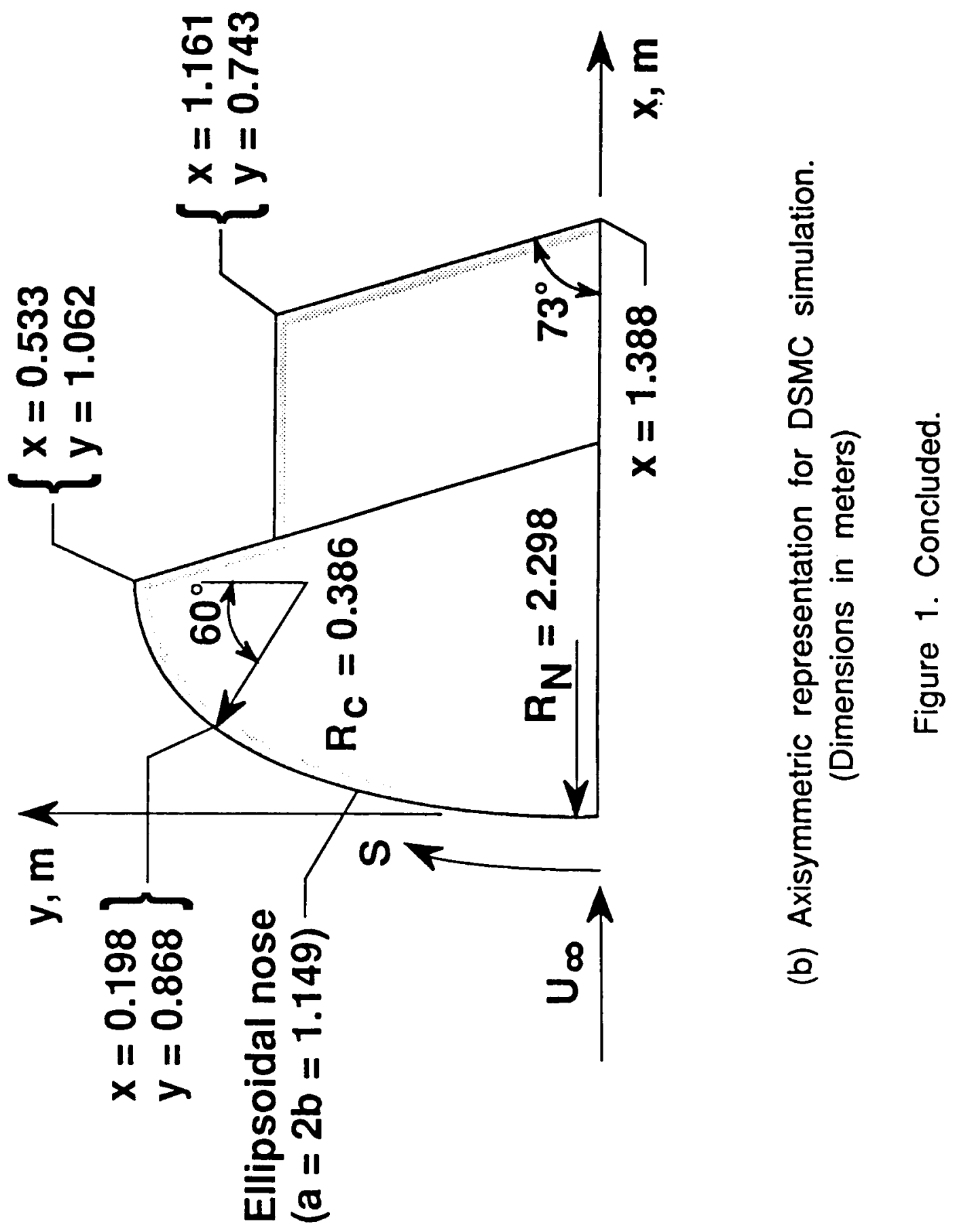




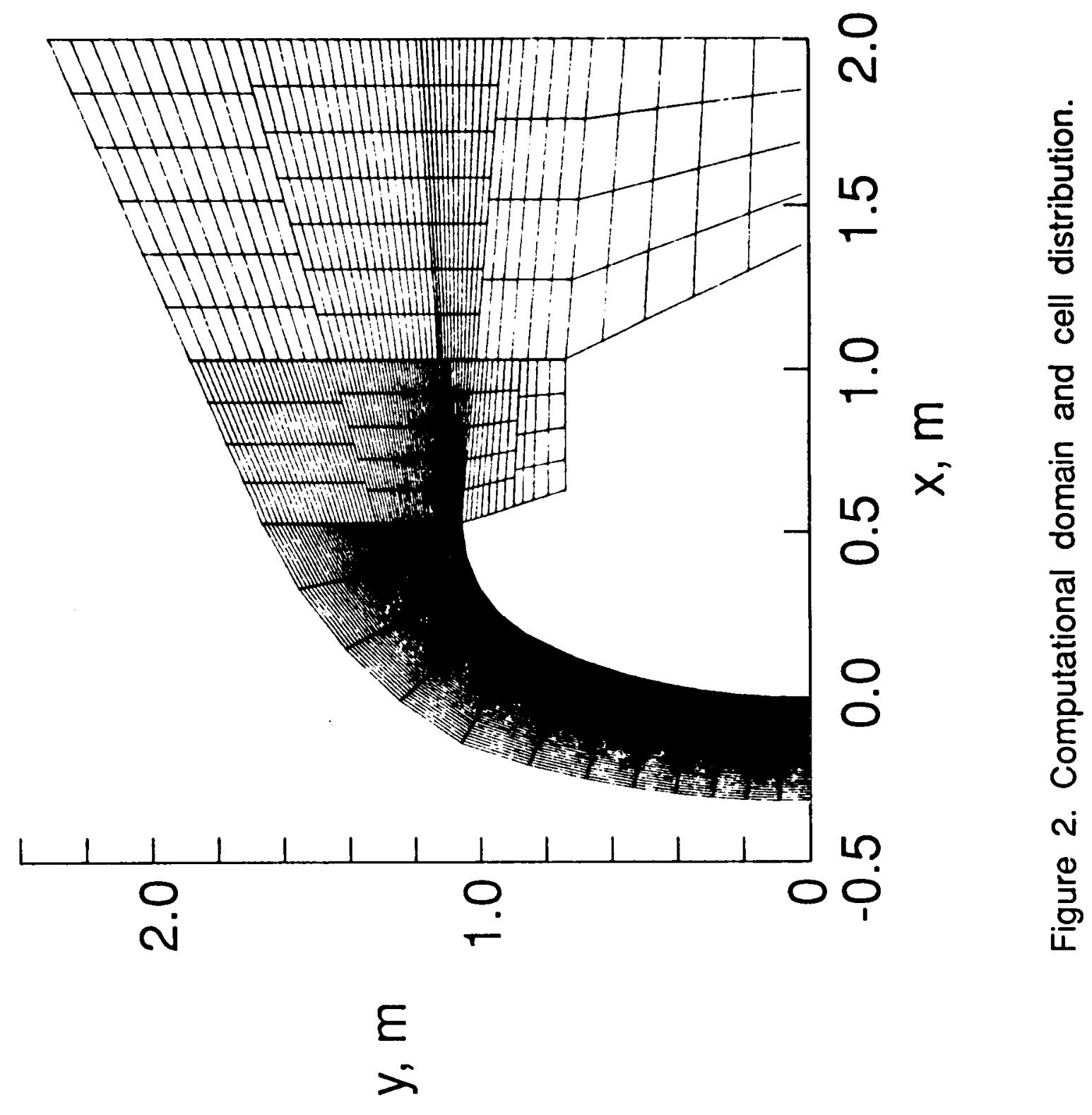




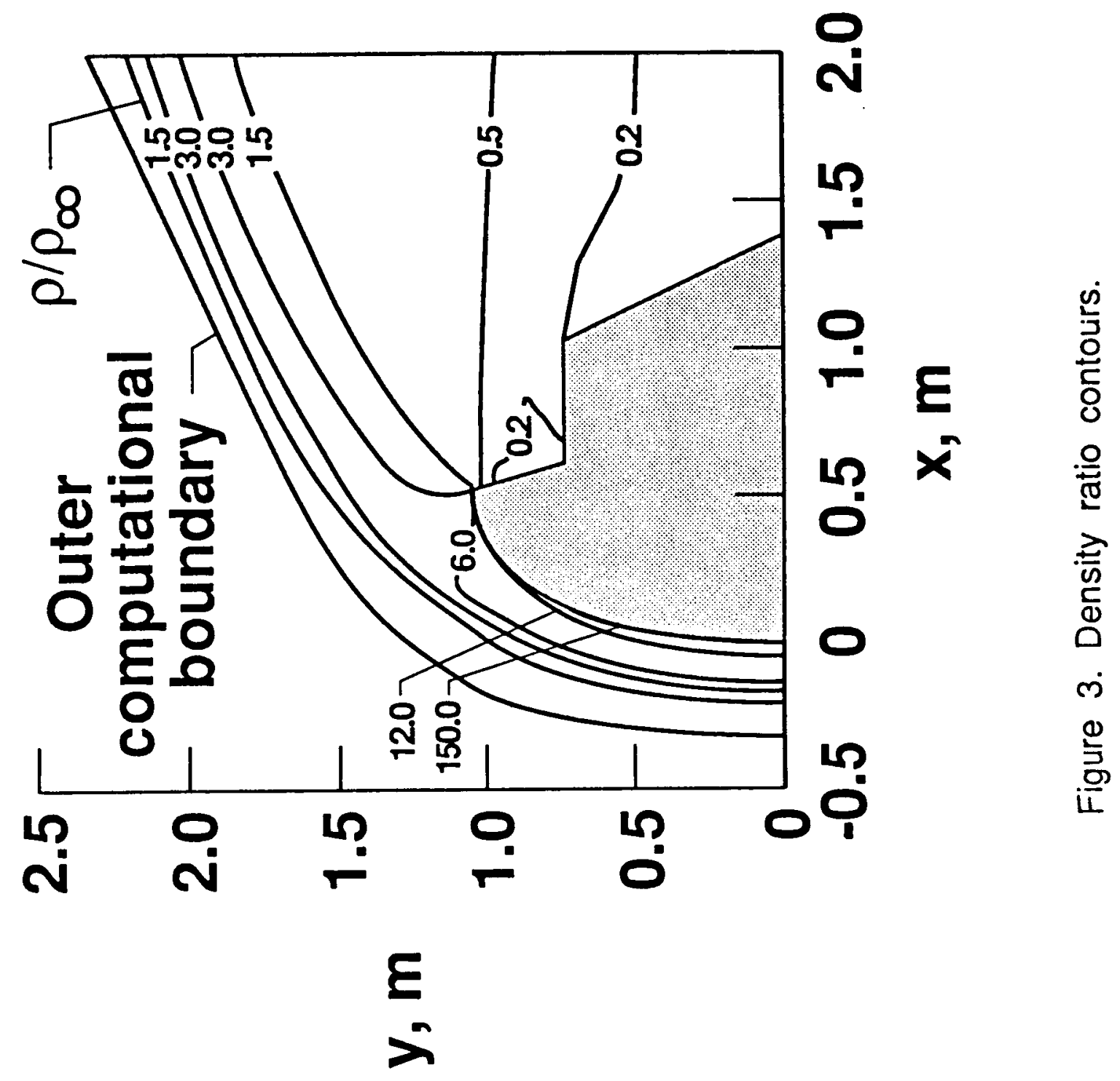




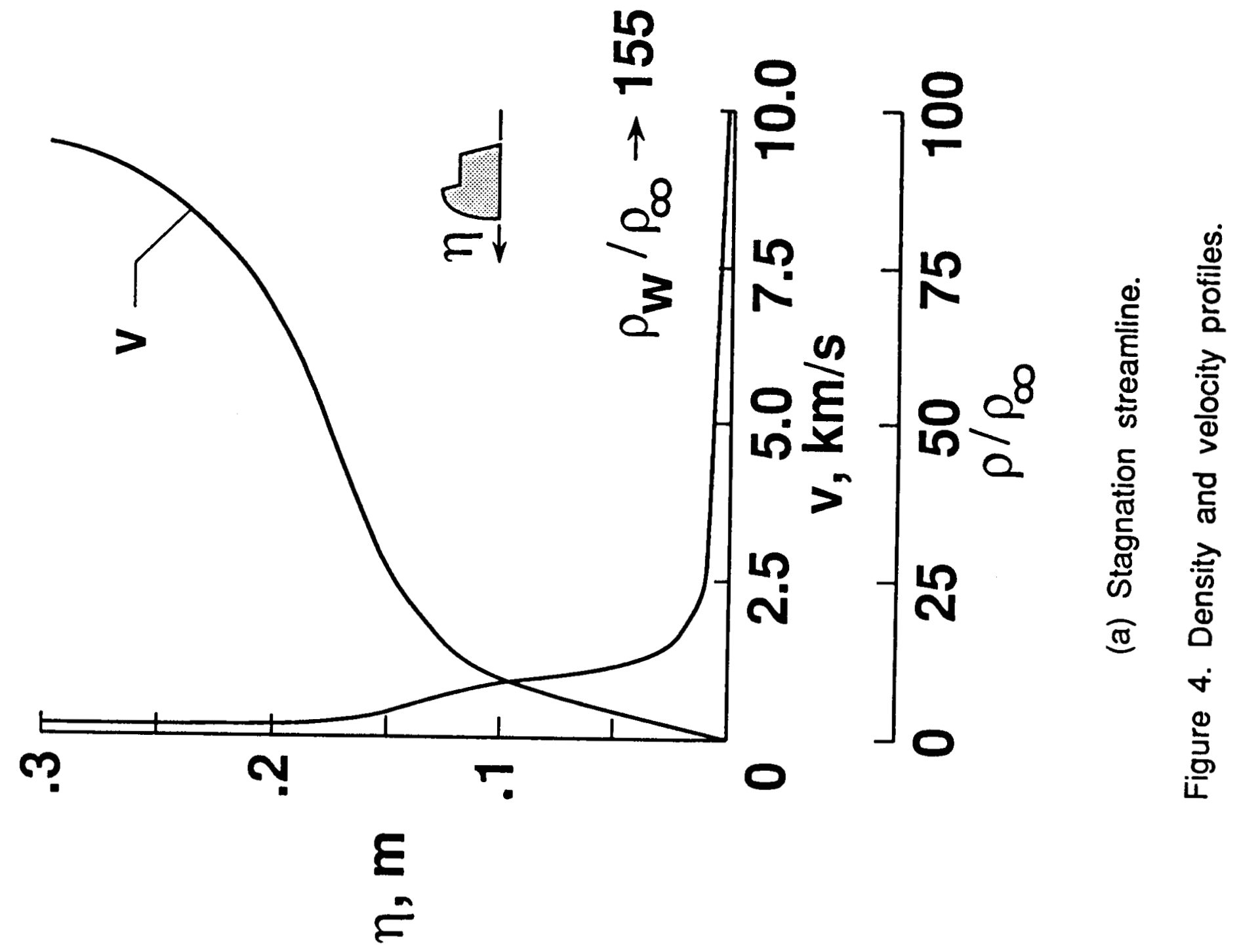




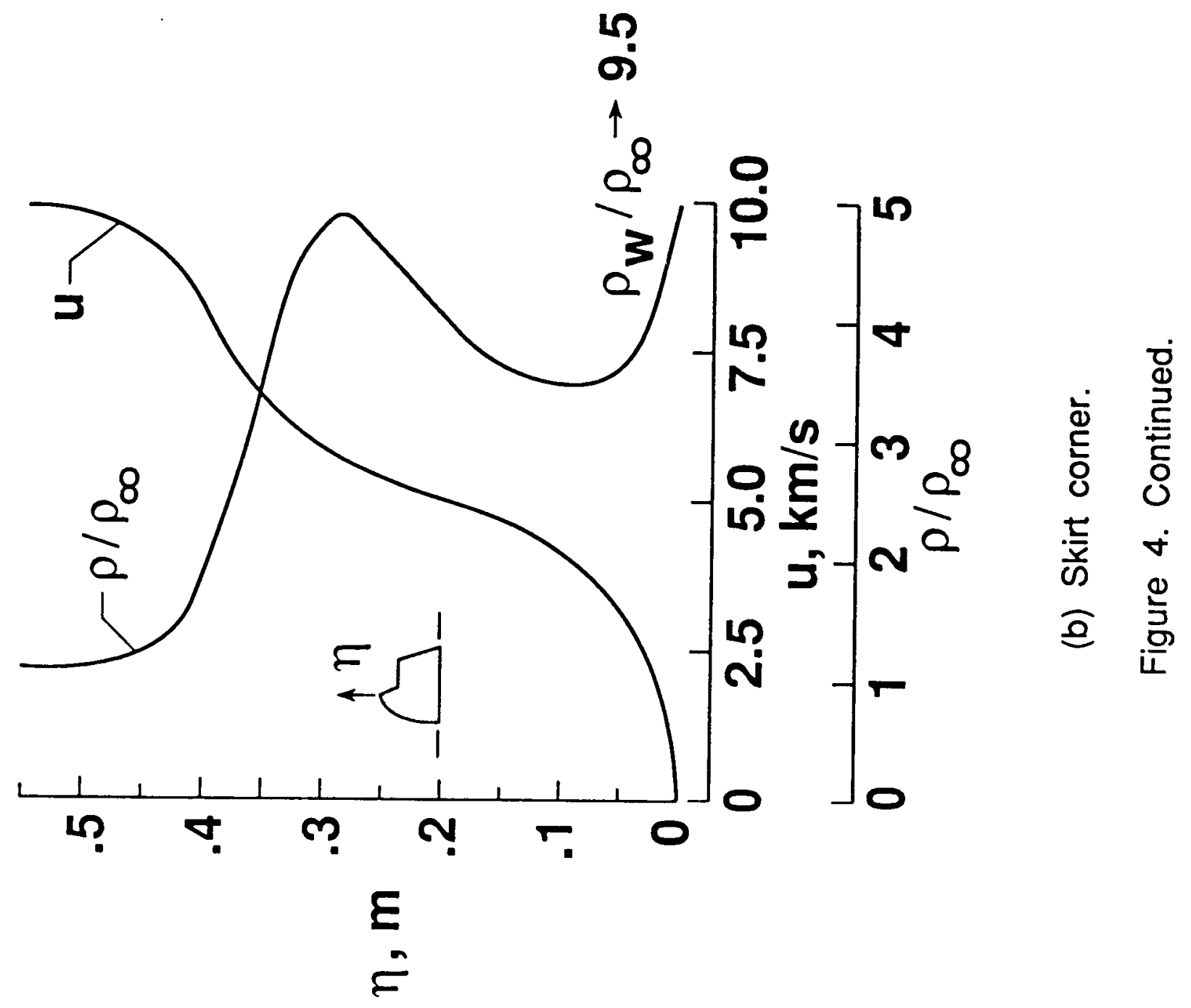




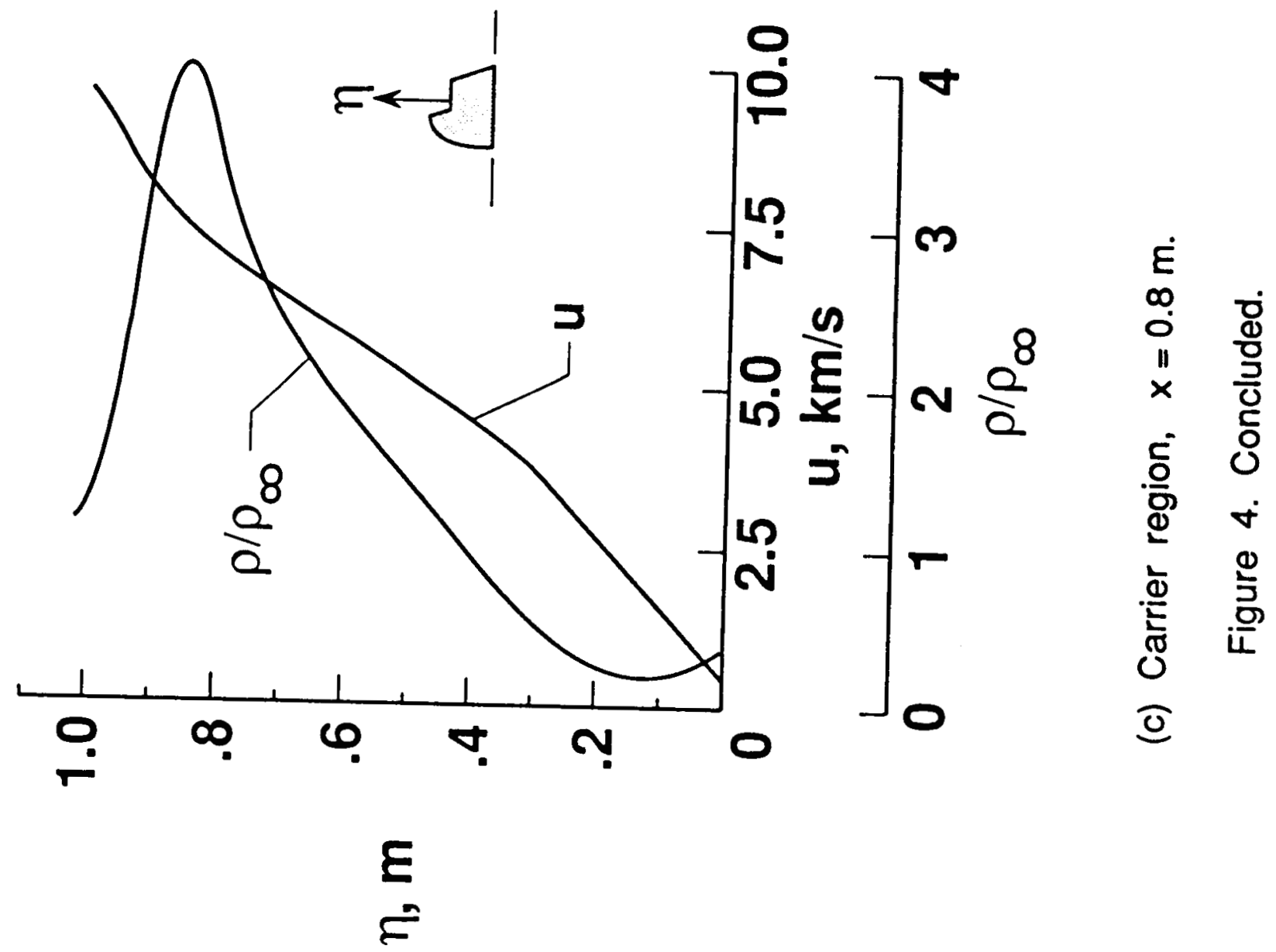




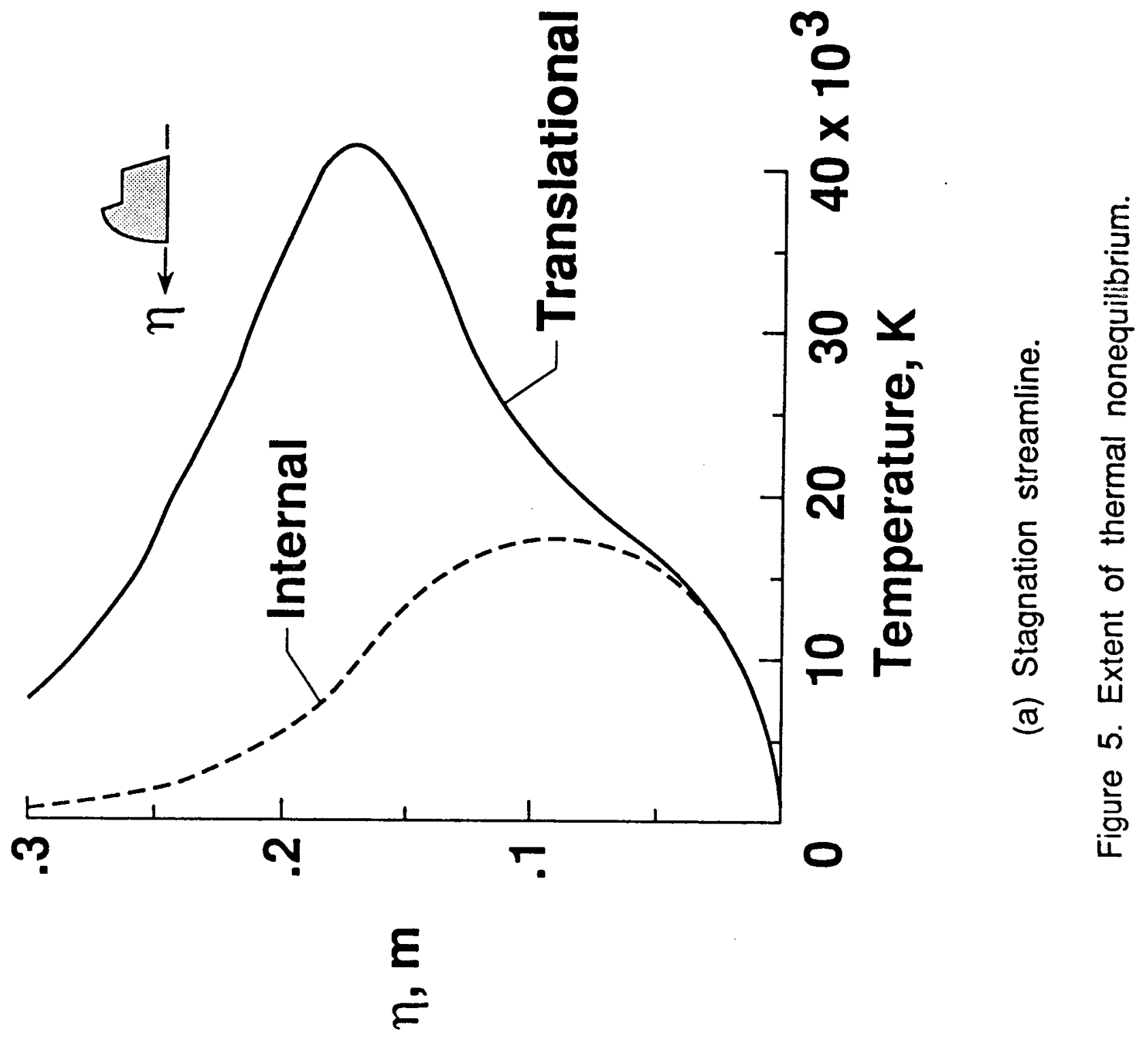




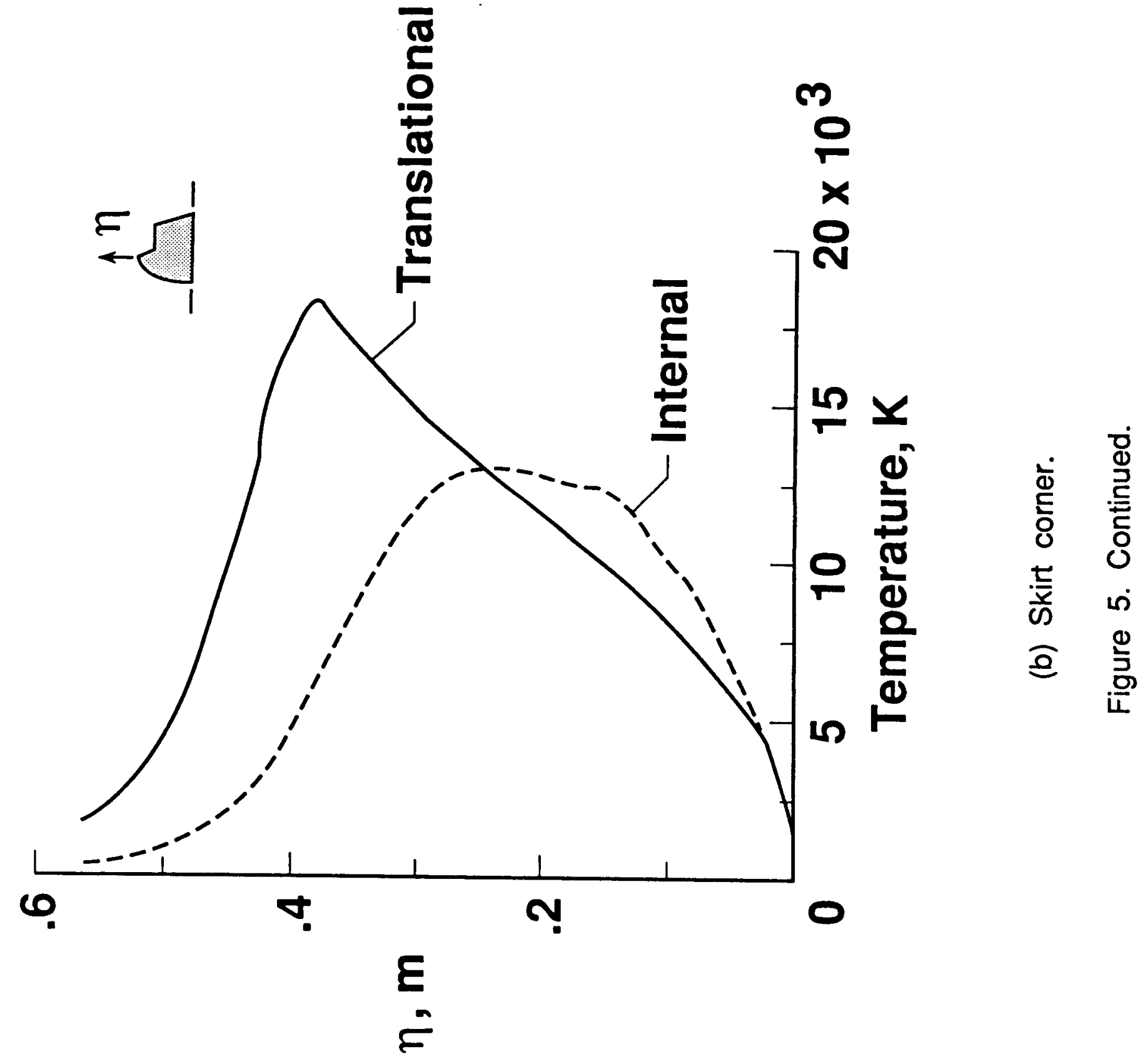




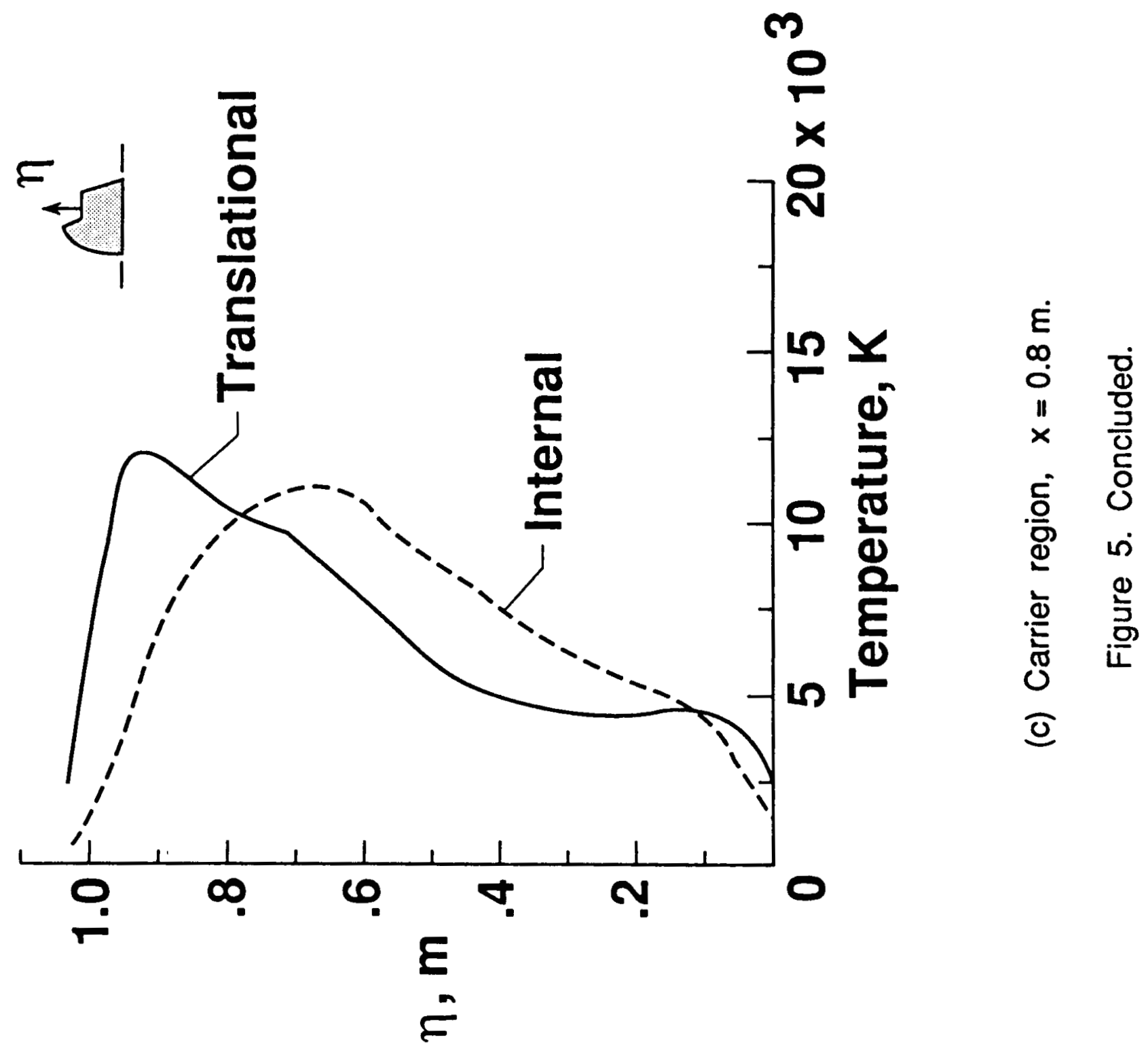




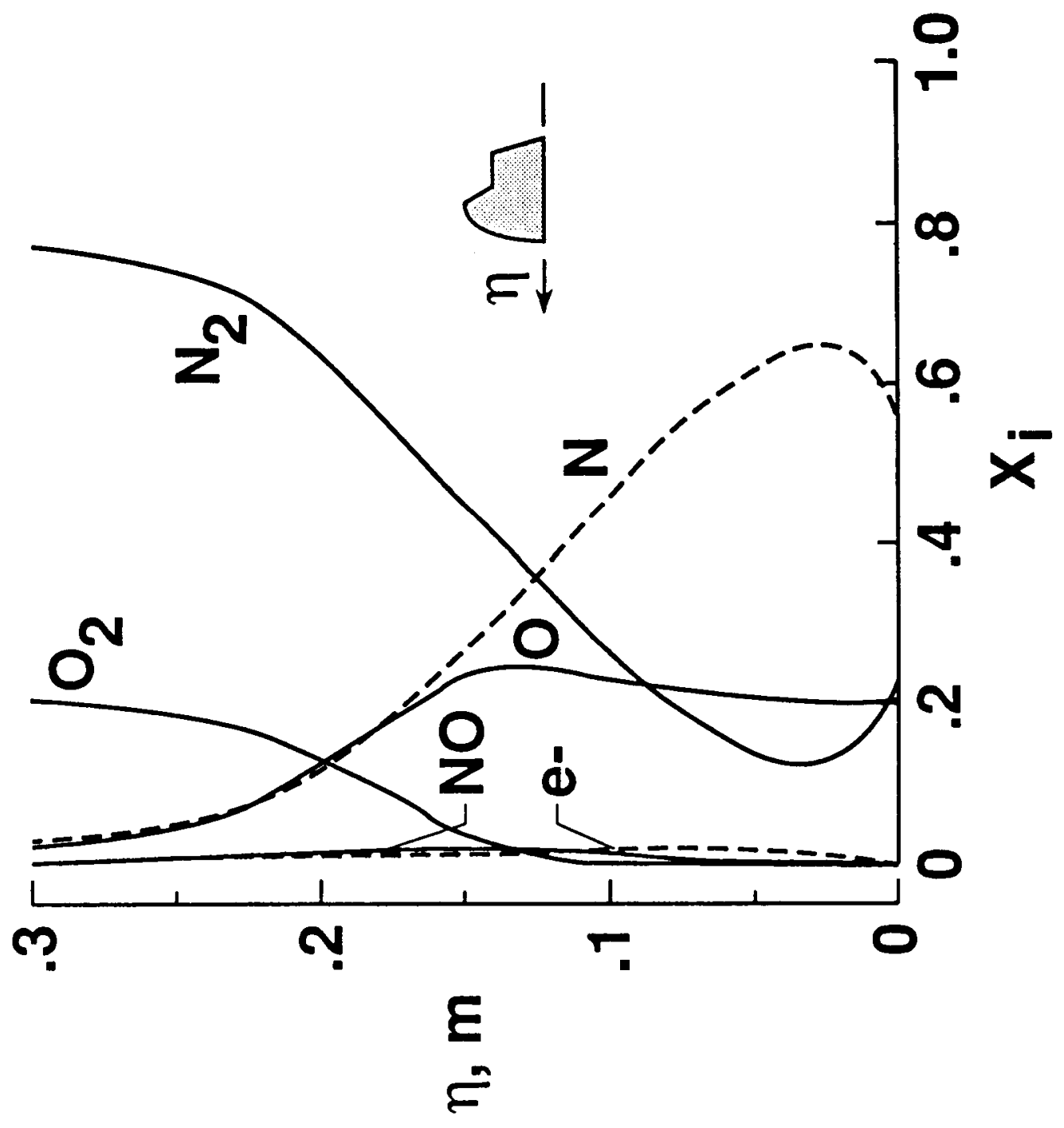

这

㽕

음

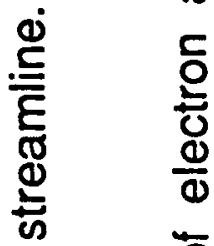

등

듕 흔

苋

क

$\frac{0}{2}$

$\dot{0}$

递 


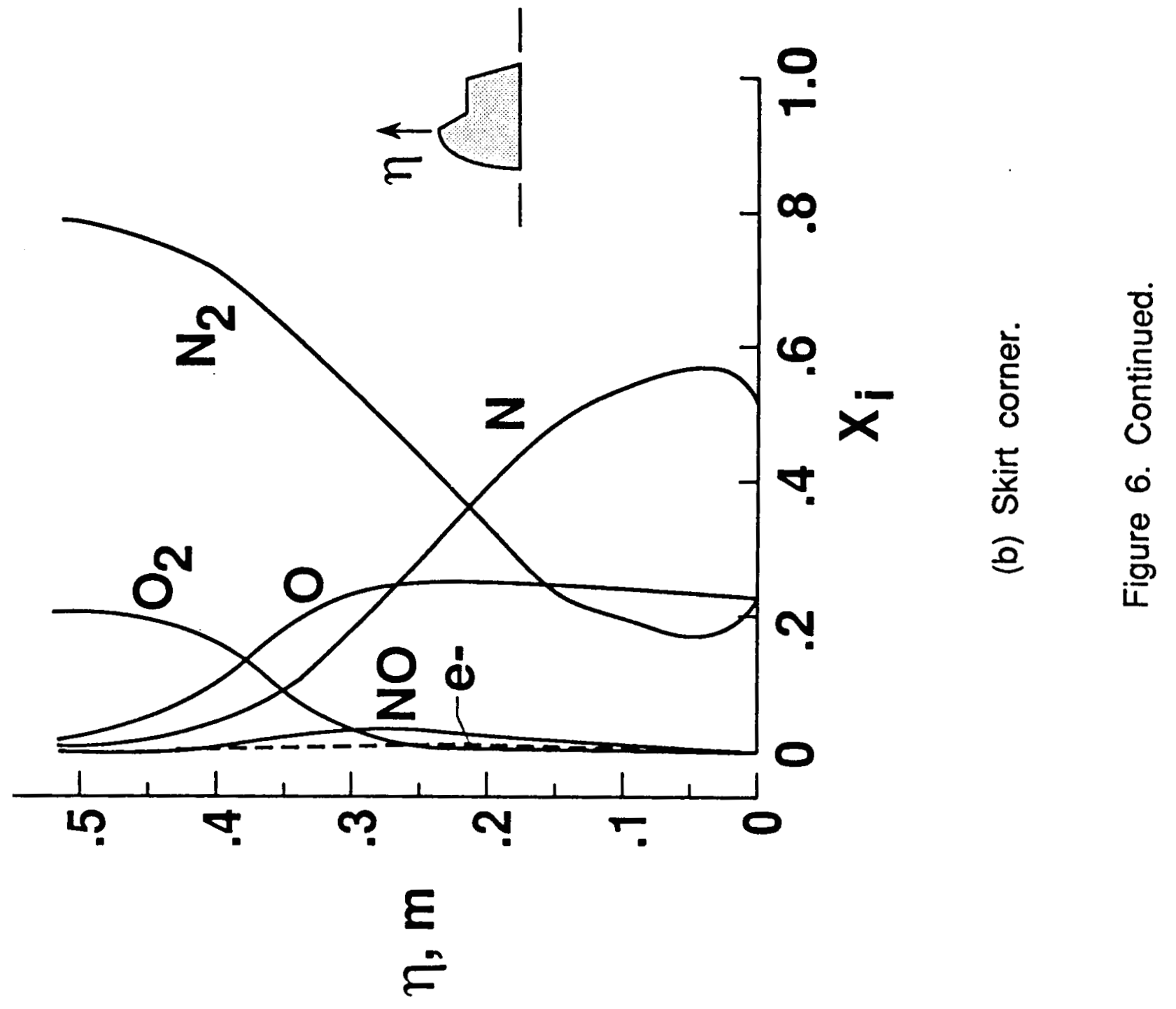




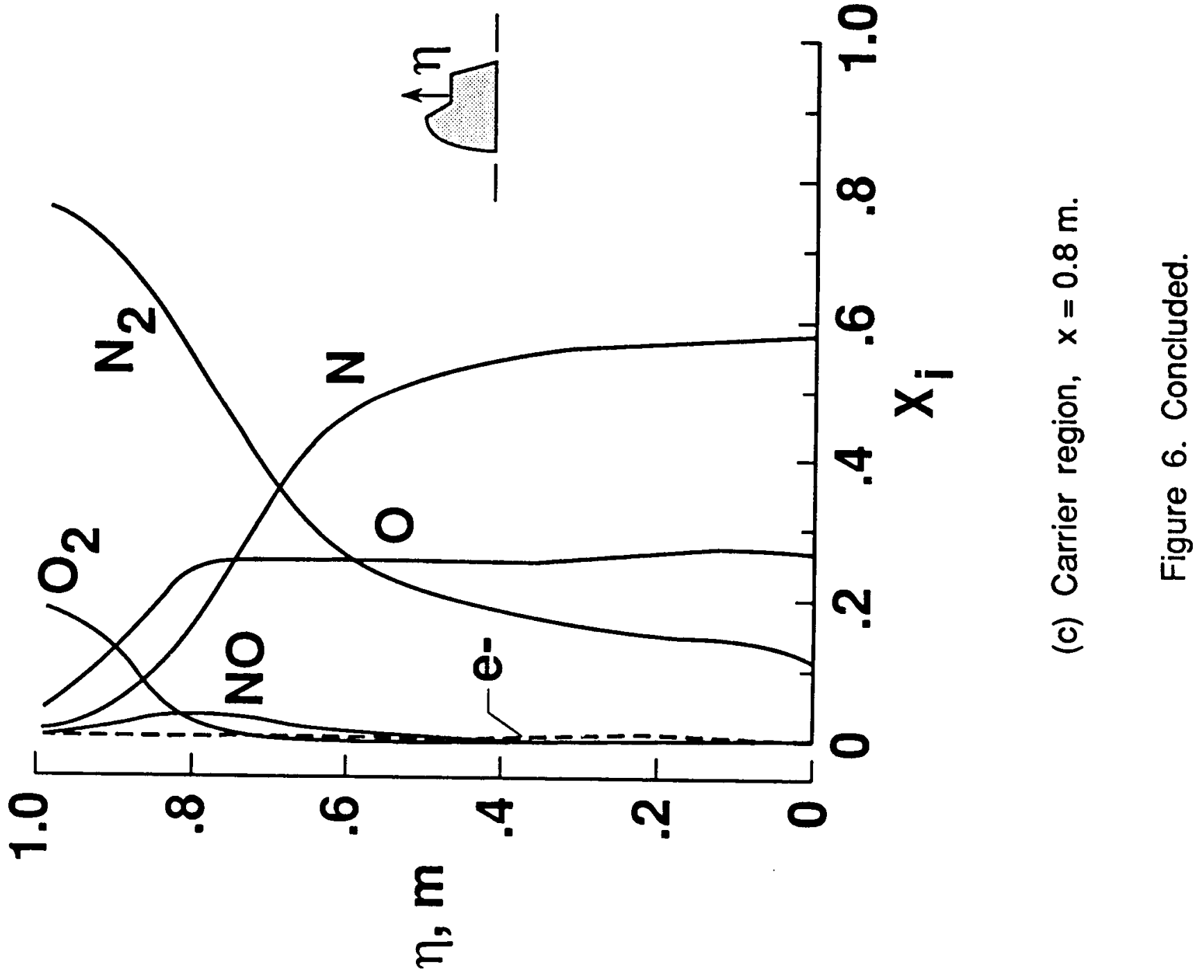




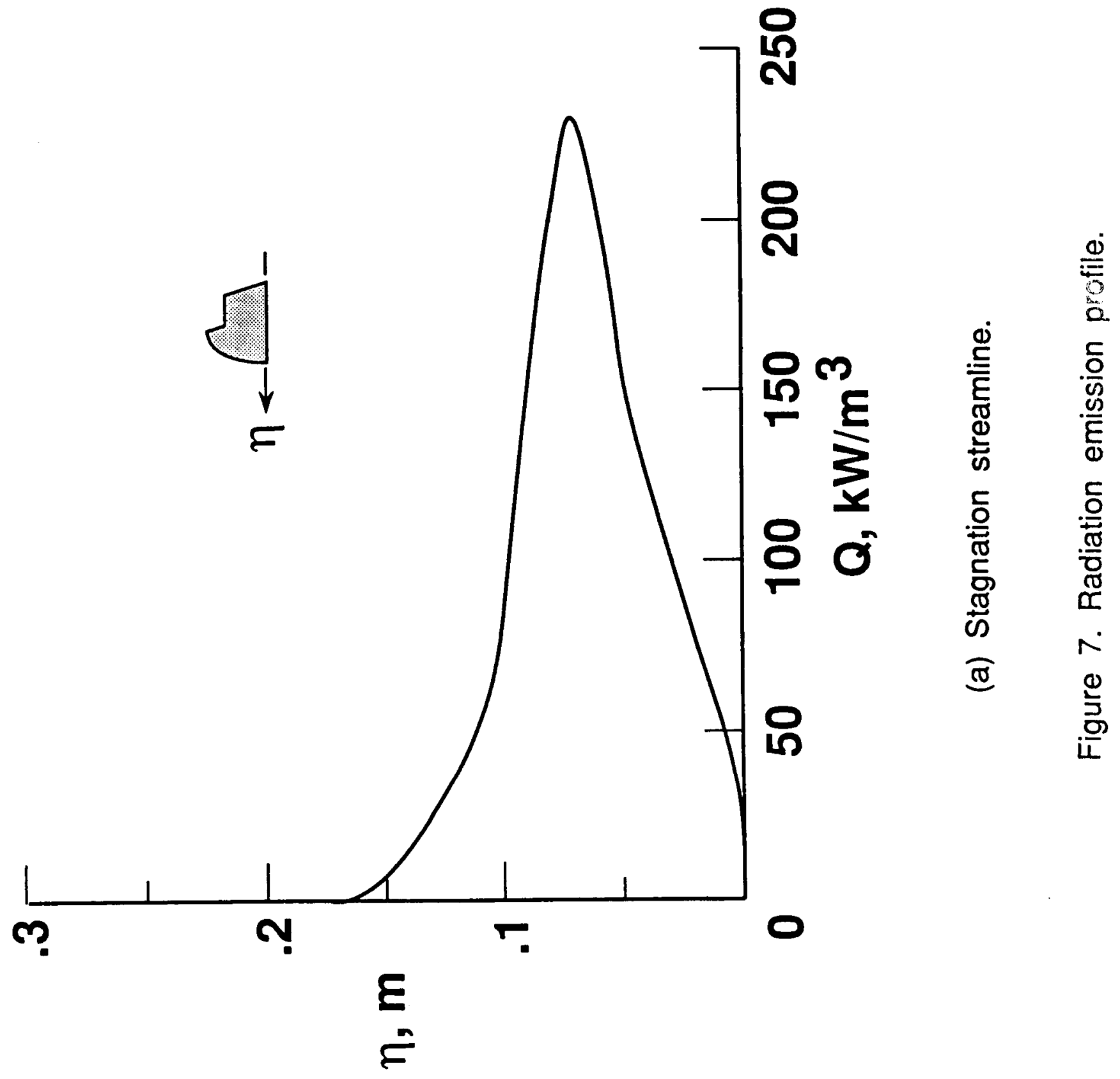




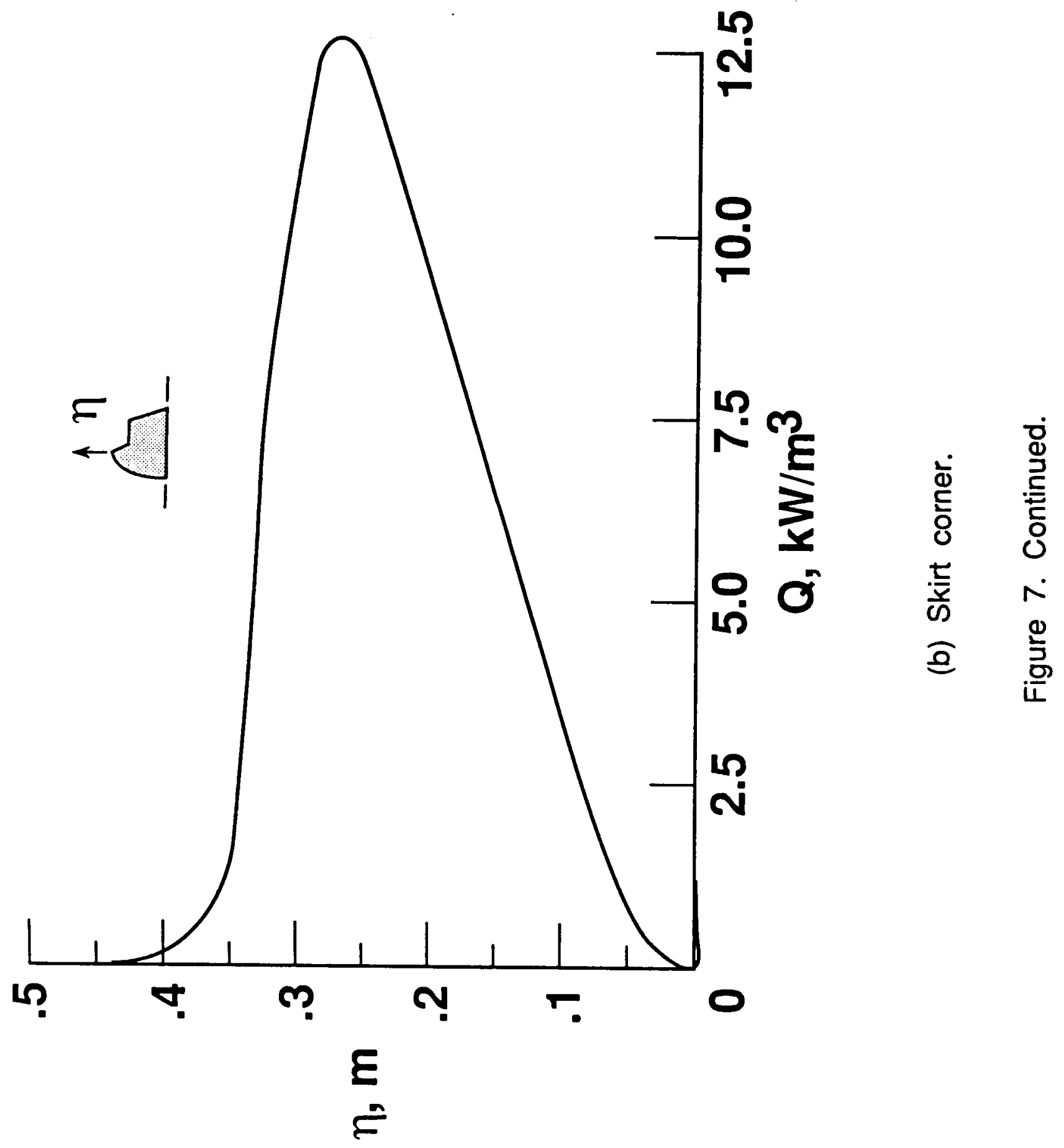




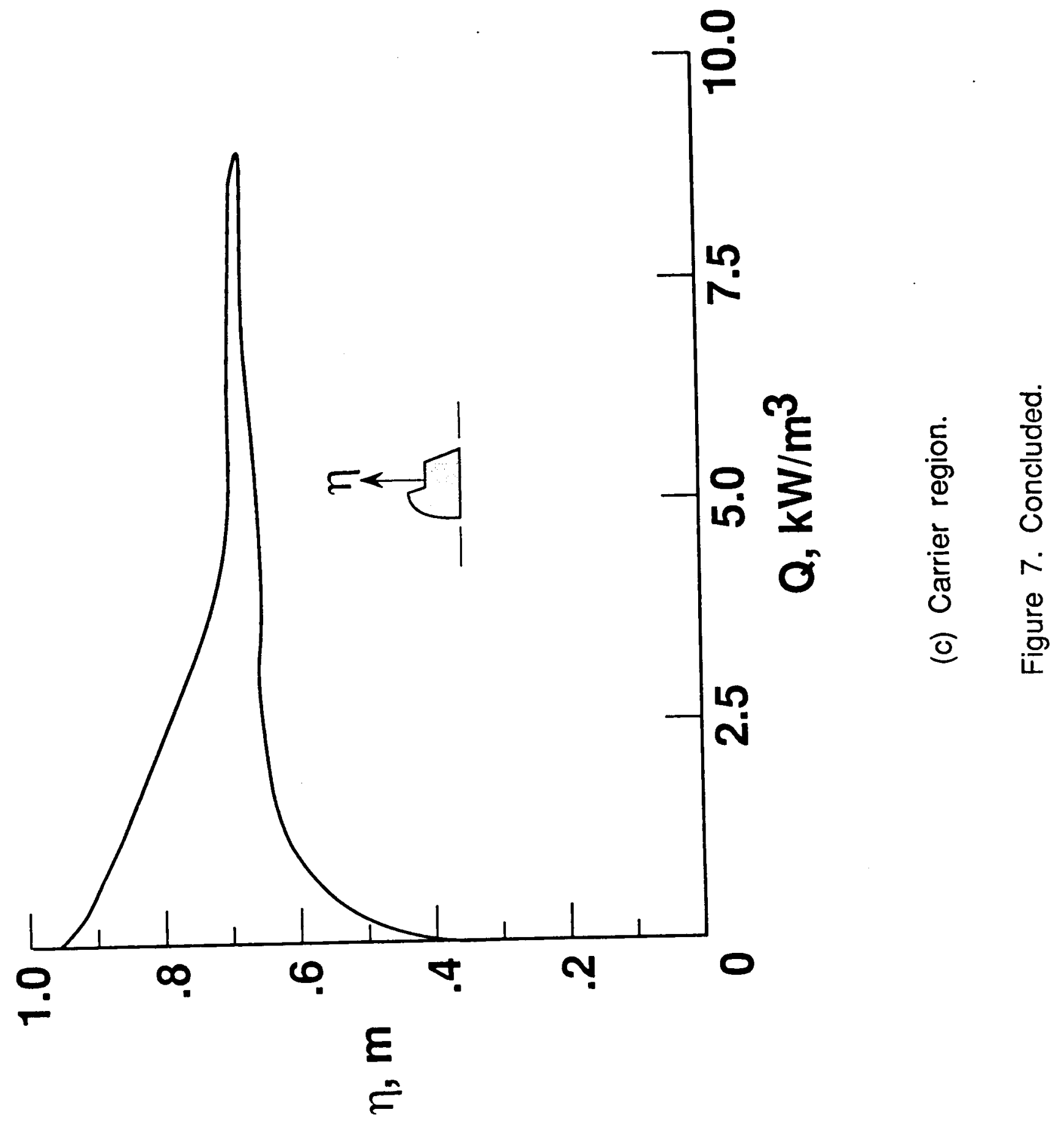




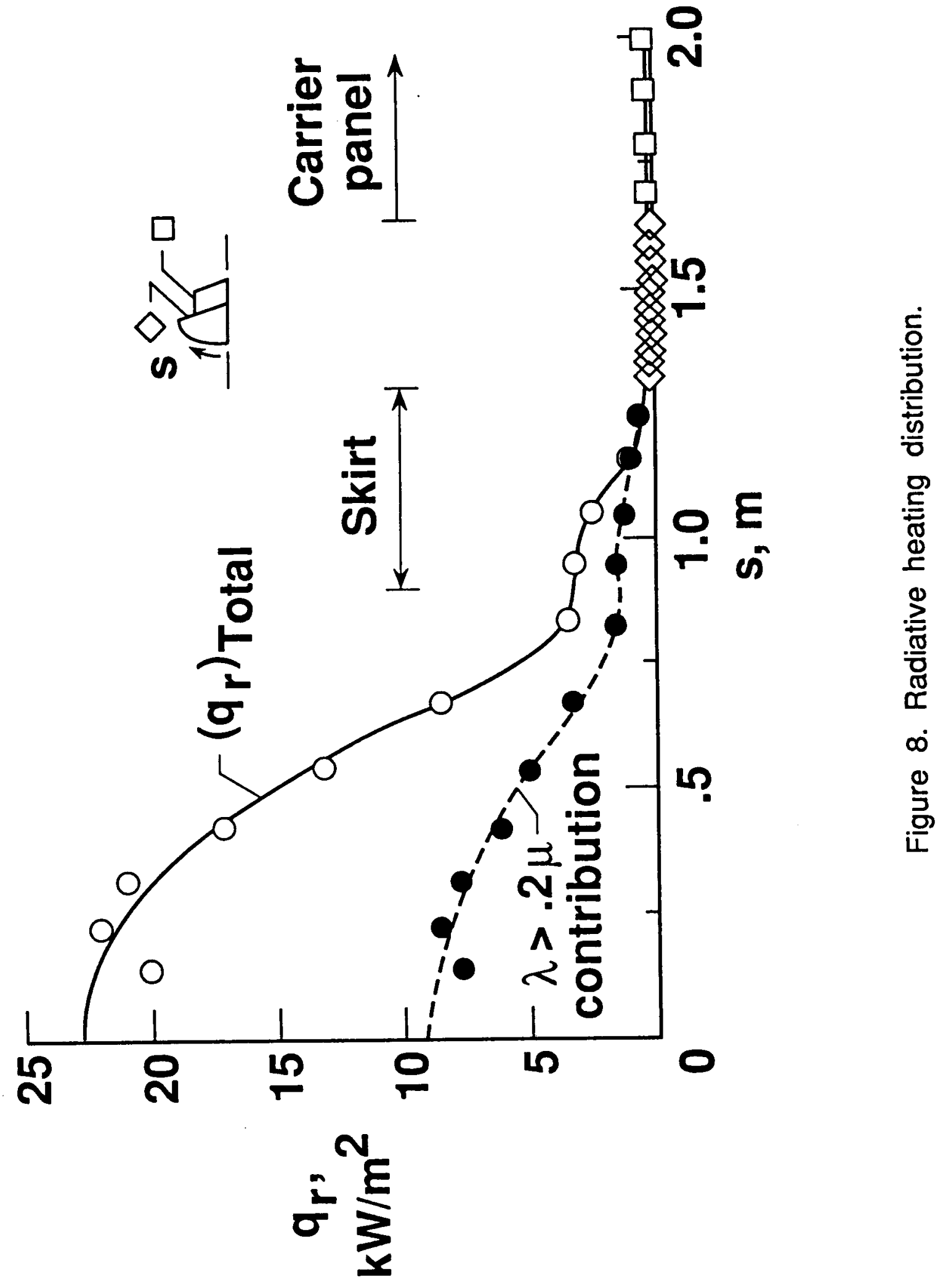




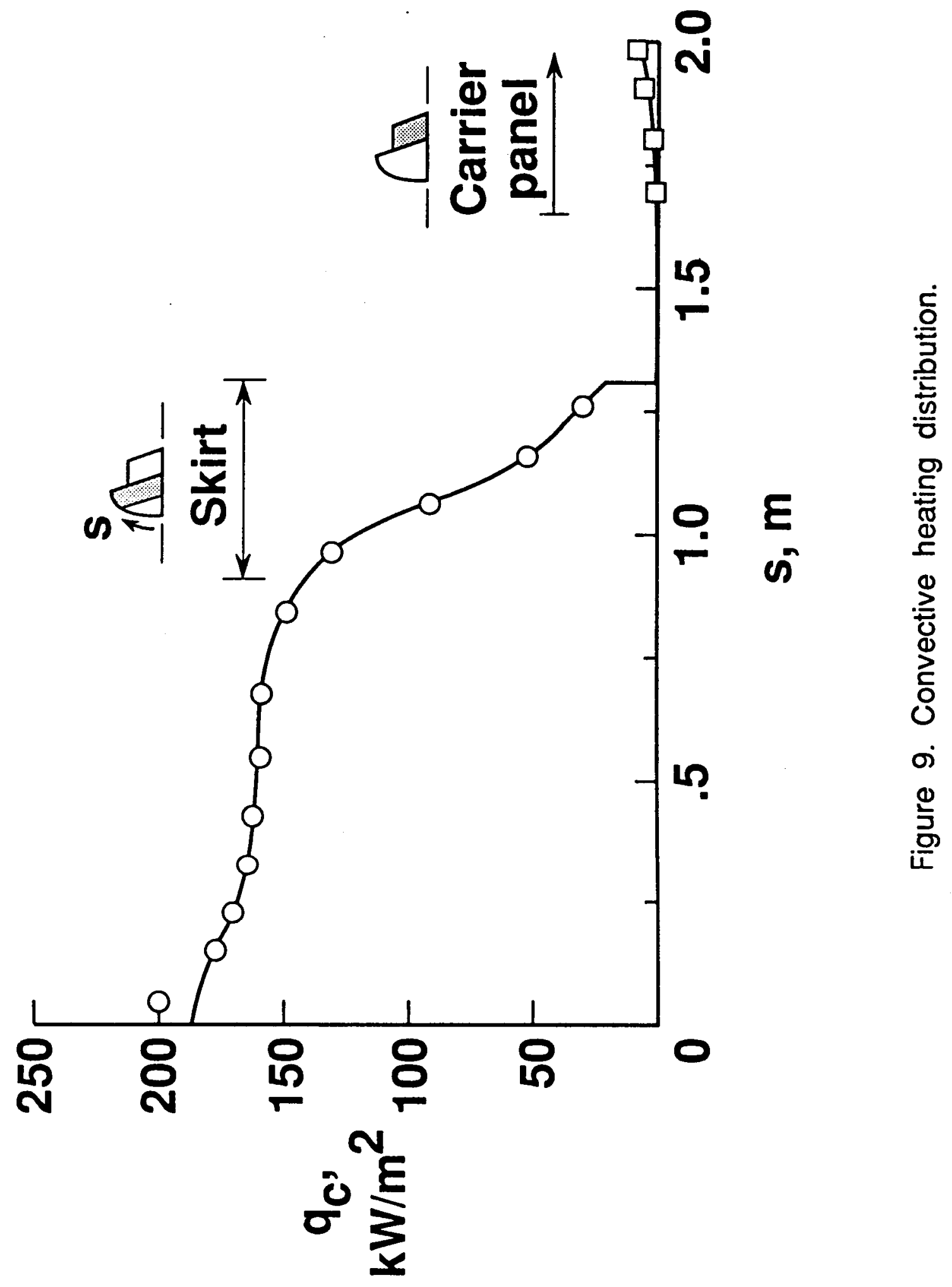




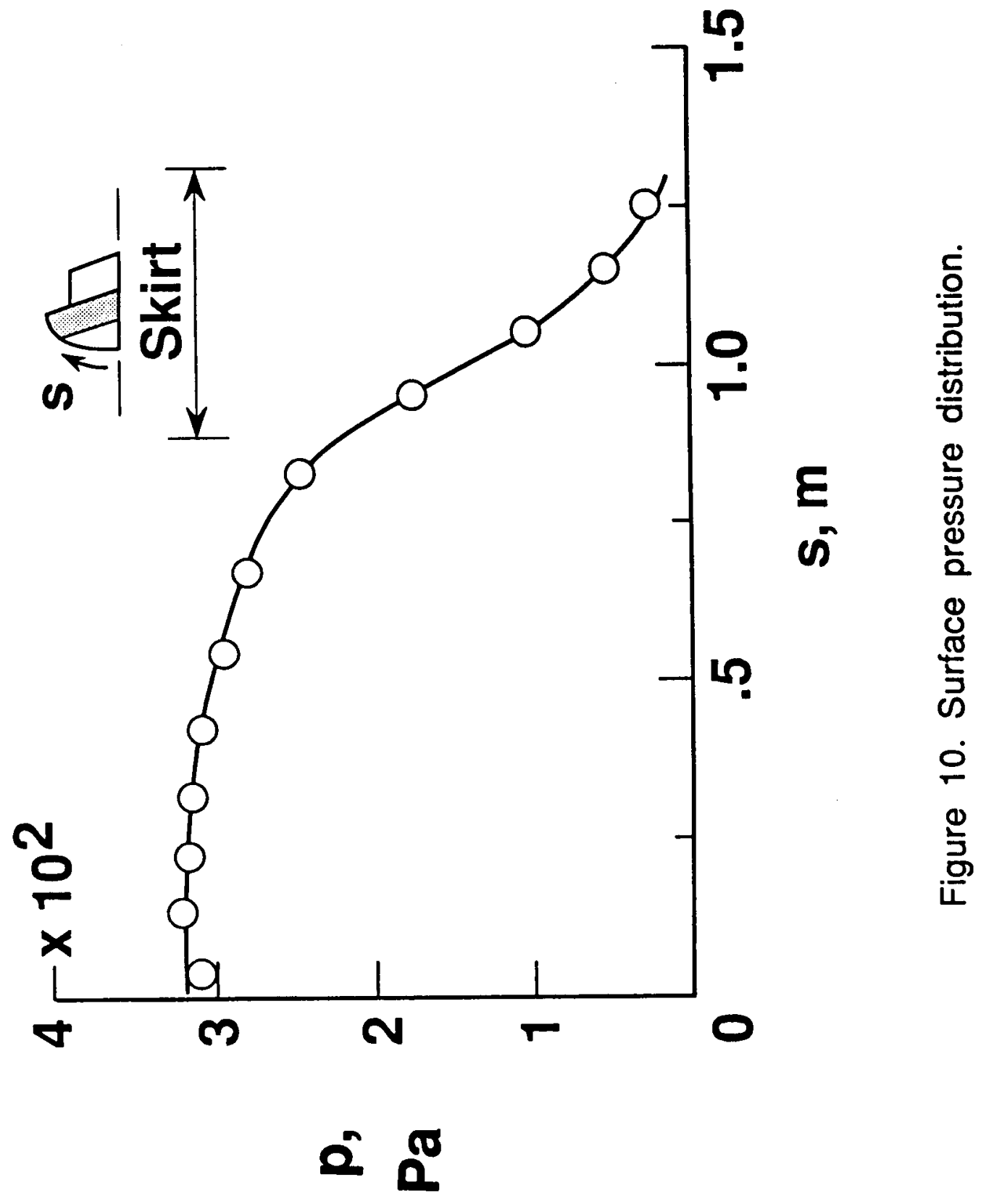




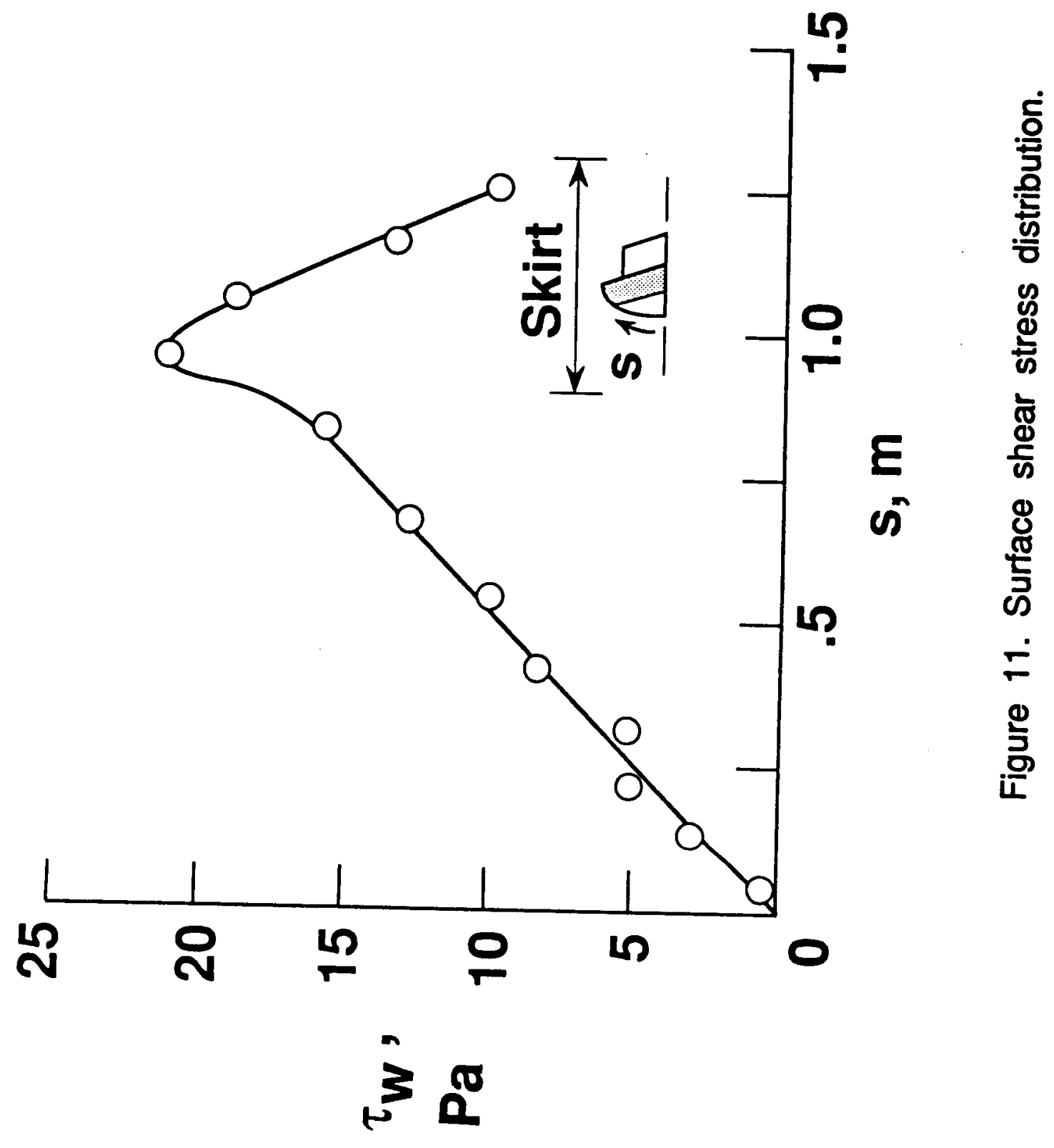


1. Report $N_{o}$

NASA TM-100673

4. Title and Subtitle

birect Simulat ion of $\Lambda F l$ forchody and Wake flow with Thermal Radiation

7. Authoris:

James $N$. Nioss

Juseph M. Price
2. Government Accession No.

1

(1)
ORIGINAL PAGE IS OF POOR QUALITY

9. Performing Organization Name and Address

VASA Langley Research Center

Hampton, VA 23665-5225

12. Sponsoring Agency Name and Address

National Aeronautics and Space Administration

Washington, DC 20546-000]

5. Report Date

Octoher 1988

6. Performing Organization Code

8. Performing Organization Report No

10. Work Unit No

$506-40-91-03$

11. Contract or Grant No

13. Type of Revort and Period Covered

Technical. Memorandum

14. Sponsoring Agency Code

15. Supplementary Notes

Presented at the Sixteenth International Symposium on Rarefied Gas

Dynamics, Pasadena, California, July 10-16, 1988. Submitted for

publication in the procuedings of the 16 th $R$ GD meeting.

16 Abstriat :

Calculated results for the flowfield structure and surface quantities are presented for an axisymmetric representation of an aeroassist fight experiment vehicle. The direct simulation Monte Carlo (DSMC) method is used to perform the calculations, since the flow is highly nonequilibrium about the vehicle during both the compression and expansion phases. The body configuration is an elliptically blunt nose followed by a skirt with a circular radius and an afterbody. Freestream conditions correspond to a single point along the entry trajectory at an altitude of $90 \mathrm{~km}$ and a velocity of $9.9 \mathrm{~km} / \mathrm{s}$. The calculations account for nonequilibrium in the translational and internal modes, dissociation, ionization, and thermal radiation. The degree of dissociation is large, but the maximum ionization is only about 2 percent by mole fraction. The blunt forebody flow experiences a high degree of thermal nonequilibrium in which the translational temperature is generally greater than the internal temperature. However, as the flow expands about the aerobrake skirt and afterbody, the internal temperature is generally greater than the translational temperature. Furthermore, the calculated results clearly show mass separation effects in the wake. The forebody heating is dominated by the convective component.

17. Key Words (Suggested by Author(s)]

Hypersonic nonequilibrium flow

Thermal radiation

Direct simulation Yonte Carlo

18. Distribution Statement

Unclassified - Unlimited

19. Security Classif. (of this revort)

20. Security Classif. (of this page)

Unclassified

Unclassified

Subject Category 34

\begin{tabular}{l|l} 
21. No. of pages & 22. Price
\end{tabular}

40

A0 3 